\title{
Método de análise de maturidade e priorização de melhorias na gestão do Processo de Desenvolvimento de Produtos
}

\author{
Carlos Alberto Cristofari Júnior ${ }^{a, *}$, Istefani Carísio de Paula ${ }^{\mathrm{b}}$, \\ Flávio Sanson Fogliatto ${ }^{c}$ \\ a,* cristofarijr@yahoo.com.br, UFRGS, Brasil \\ bistefani@producao.ufrgs.br, UFRGS, Brasil \\ cffogliatto@producao.ufrgs.br, UFRGS, Brasil
}

\begin{abstract}
Resumo
o Processo de Desenvolvimento de Produtos (PDP) é um procedimento de negócio cada vez mais decisivo nos resultados estratégicos das empresas que dele dependem. A tarefa de identificar oportunidades de melhoria na gestão deste processo complexo não é trivial e tem incentivado vários pesquisadores a propor abordagens para tornar mais racional o esforço de sofisticação da gestão do PDP (GPDP). Este artigo tem por objetivo apresentar um método gerencial aplicável ao diagnóstico da maturidade da GPDP e à priorização de melhorias neste procedimento. 0 diagnóstico da maturidade proposto é realizado através do relacionamento entre a frequência da ocorrência de problemas típicos do PDP e dez áreas do conhecimento da GPDP. A partir deste relacionamento são identificadas as áreas de gestão em estado crítico e que merecem atenção gerencial. Estas áreas são desdobradas em melhores práticas, que se afiguram como oportunidades de melhoria, as quais são priorizadas utilizando-se uma matriz MAUT (Multiattribute Utility). 0 método foi aplicado em uma empresa de desenvolvimento de software, na forma de estudo de caso, e se mostrou adequado.
\end{abstract}

Palavras-chave

Gestão do PDP. Melhoria de PDP. Modelos de maturidade.

\section{Introdução}

0 reconhecimento de que a forma como as empresas desenvolvem seus produtos influencia no sucesso dos mesmos e, por consequência, no sucesso mercadológico do empreendimento, levou diversos autores a pesquisarem as razões do êxito e do fracasso das organizações no desenvolvimento de seus produtos. Várias dessas pesquisas, como, por exemplo, Edgett e Kleinschmidt (2004a, b, c) Page (1993), Griffin (1997), Oakley (1997), Dooley Subra e Anderson (2001), Kahn (2001), Cooper et al., (2004a; b; c), Adams-Bigelow (2005), Barckzak et al., (2006) indicaram que empresas bem sucedidas no desenvolvimento de produtos procediam de maneira similar no tocante a atividades depois denominadas melhores práticas de desenvolvimento de produtos.

Como decorrência prática dessas pesquisas, empresas vêm buscando institucionalizar as melhores práticas de desenvolvimento de produto em seu cotidiano por meio da formalização das etapas do PDP. Salviano (2006) assegura que, em uma empresa, a institucionalização de processos de gerenciamento, como a GPDP, é um processo de mudança que deve ser planejado e implementado em etapas. Entretanto, a simples formalização das atividades na forma de manuais, modelos ou gráficos não agrega necessariamente melhorias ao PDP; para obtê-las, é necessário que aspectos estratégicos e de suporte sejam considerados conjuntamente.

Trabalhos com diferentes abordagens foram desenvolvidos visando tornar mais ágil, efetiva e/ou mensurável a tarefa melhorar a gestão de processos como o PDP. Entre eles, podem-se citar Crosby (1984), Caffyn (1998), Rentes (2000), CMMI (2002), Rozenfeld, Scalice e Amaral (2005), Gusberti (2006), Kahn, Barzack e Moss (2006) e Moultrie, Clarckson e Probert (2006). Agostinetto e Amaral (2005) destacam pelo menos três abordagens, amplamente difundidas na década de 90, para efetivar melhoria contínua (MC) de processos, conforme apresentado no Quadro 1. 
Quadro 1. Diferentes abordagens para melhoria de processos.

\begin{tabular}{|c|l|l|}
\hline Abordagem & \multicolumn{1}{|c|}{ Origem } & \multicolumn{1}{|c|}{ Escopo } \\
\hline $\begin{array}{c}\text { Gerenciamento de mudanças } \\
\text { (Change Management) }\end{array}$ & $\begin{array}{l}\text { Evolução da MC de processo e das técnicas } \\
\text { de planejamento estratégico }\end{array}$ & $\begin{array}{l}\text { Processo contínuo de planejamento e implantação de } \\
\text { mudança organizacional sustentada }\end{array}$ \\
\hline $\begin{array}{c}\text { Organização que aprende } \\
\text { (Learning Organization) }\end{array}$ & $\begin{array}{l}\text { Evolução da MC de processo e do conceito } \\
\text { de aprendizagem organizacional }\end{array}$ & $\begin{array}{l}\text { Processo contínuo de integração e aquisição de novos } \\
\text { processos para elevar o nível de tomada de decisão }\end{array}$ \\
\hline $\begin{array}{c}\text { Modelos de maturidade } \\
\text { (Maturity Models) }\end{array}$ & $\begin{array}{l}\text { Evolução da MCcom ênfasena implantação } \\
\text { gradativa de novos processos }\end{array}$ & $\begin{array}{l}\text { Processo contínuo de análise da competência da } \\
\text { organização para nortear ações de melhoria }\end{array}$ \\
\hline
\end{tabular}

Fonte: Agostinetto e Amaral (2005).

Os modelos de maturidade referidos no Quadro 1 têm sido considerados importante ferramenta para avaliar a competência da empresa em relação a processos de gestão específicos. A importância desses modelos é reconhecida principalmente na avaliação da sofisticação de processos complexos que permeiam toda a organização e cuja execução está alocada a vários setores. Tal característica torna complexo o trabalho de mensuração e a proposição de melhorias nos processos.

Este artigo apresenta um método inovador e abrangente que permite diagnosticar a maturidade da gestão do PDP a partir da frequência da ocorrência de problemas no PDP no cotidiano das empresas. De modo geral, o objetivo é explicitar as áreas menos desenvolvidas do PDP, as quais estão relacionadas com os problemas, para que sejam priorizadas quando da implantação de ações de melhoria. Duas contribuições se destacam no método proposto: (i) a utilização de um questionário onde a intensidade de ocorrência de problemas típicos do PDP é avaliada pelos respondentes; e (ii) a priorização das áreas do PDP para implantação de melhorias, utilizando a estrutura de matrizes do QFD (Quality Function Deployment ou Desdobramento da Função Qualidade).

A pesquisa apresentada neste artigo classifica-se, quanto à sua natureza, como pesquisa aplicada, pois o objetivo é a aplicação de novos conceitos na área de desenvolvimento de produtos, visando melhorias ou adaptações no processo de desenvolvimento de produtos em empresas industriais (CERVO; BREVIAN, 1996). Quanto a sua contribuição principal, caracteriza-se como pesquisa descritiva, pois tem por objetivo descrever as características da gestão do PDP e estabelecer relações entre as propriedades deste tema consideradas no artigo.

A classificação quanto à abordagem e ao procedimento metodológico demanda dividir a pesquisa em duas etapas: a construção do método proposto e a aplicação desse método, pesquisa quantitativa, realizada através de questionário fechado aplicado a especialistas (Método Delphi adaptado) (MITCHELL; JOLLEY, 2003). A segunda etapa é classificação quanto à abordagem como pesquisa quantitativa, realizada ao longo de um estudo de caso (YIN, 2002).
0 restante deste artigo está dividido em quatro seções. Na seção 2 apresenta-se o referencial teórico, com ênfase na análise dos modelos de maturidade. A seção 3 detalha a proposta metodológica. $\mathrm{Na}$ seção 4 reporta-se uma aplicação prática do método proposto em uma empresa de desenvolvimento de software. Na seção 5 apresentam-se conclusões e sugestões para desenvolvimentos futuros.

\section{Fundamentação teórica}

A Gestão do Processo de Desenvolvimento de Produtos (GPDP) é extensa e está em constante evolução, pois o próprio PDP assumiu nas últimas décadas aspectos de processo de negócios, envolvendo a empresa como um todo (ROZENFELD et al., 2006; GONÇALVES, 2000). Essa visão contemporânea de gestão do negócio centrada no desenvolvimento de produtos, ao invés do processo de desenvolvimento de produtos centrado em engenharia, trouxe vários benefícios para as empresas (PATTERSON; FENOGLIO, 1999). Essa perspectiva permite visualizar, de forma natural, a cadeia de atividades ordenadas cronologicamente e a interseção dos subprocessos acionados ao longo de todo o ciclo de vida do produto (MUNDIM et al., 2002).

0 PDP é um procedimento que lida com informações do mercado e da empresa para materializar necessidades dos consumidores na forma de produtos ou serviços (ROMANO, 2003). Esse processo transpassa vários setores funcionais demandando a interação de quase todos os processos empresariais. Por apresentar essa característica multifuncional, o desenvolvimento de produtos apresenta riscos e incertezas intrínsecos, envolvendo constantemente a tomada de decisão com potencial impacto em situações futuras (THEVENOT et al., 2006).

A qualidade da GPDP está intimamente ligada à padronização do PDP. Modelos de referência (e.g., PAHL et al., 2005; BAXTER, 1998; ROMANO, 2003; PAULA; RIBEIRO, 2007; ROZENFELD et al., 2006) e guias de melhores práticas (e.g., PDMABOK, 2003; PROJECT MANAGEMENT INSTITUTE, 2004) fornecem suporte a essa padronização. Ambos têm 
por objetivo institucionalizar as melhores práticas relacionadas à gestão do PDP, contribuindo para o amadurecimento das empresas.

Para facilitar o gerenciamento do PDP e reduzir riscos e incertezas, o PDP é usualmente descrito em função de três macrofases: pré-desenvolvimento, desenvolvimento e pós-desenvolvimento (ROZENFELD et al., 2006; PDMABOK, 2003; PAULA; RIBEIRO, 2007; ROMANO, 2003). A divisão em macrofases, com seus objetivos específicos, auxilia as empresas a se organizar e difundir as melhores práticas, que são chaves para a sofisticação da GPDP na empresa. A macrofases são cíclicas e normalmente desenvolvem-se simultaneamente na empresa, já que vários projetos, em fases distintas, evoluem concomitantemente (PDMABOK, 2003).

Rozenfeld et al. (2006) ressaltam que há subprocessos vitais para o bom encadeamento das atividades que permeiam todas as fases e são responsáveis, por exemplo, pela provimento dos recursos e comunicação, suportes essenciais à execução do projeto. Embora tais subprocessos estejam bem delineados na literatura, profissionais de PDP encontram dificuldades para sofisticar a gestão deste processo (AGOSTINETTO; AMARAL, 2005). Esses obstáculos podem originar-se de causas diversas, advir da cultura da empresa, relacionar-se ao tipo de produto desenvolvido ou à capacidade dos profissionais que gerenciam os subprocessos que o PDP mobiliza. Para Nilsson-Witell, Antoni e Dahlgaard (2005), essas dificuldades interferem na sustentabilidade das melhorias propostas principalmente quando os gestores procuram implementar mudanças abrangentes com uma única intervenção.

\subsection{Modelos de maturidade}

Modelos de maturidade são estruturas utilizadas como ferramentas de melhoria de processo, à medida que descrevem o processo em patamares de sofisticação com o intuito de orientar o esforço de melhoria. A seguir são apresentados o conceito de maturidade, uma tipologia proposta por Fraser, Moultrie e Gregory (2002) e uma análise comparativa entre os tipos de modelo de maturidade.

Atribui-se a Crosby (1984) que, no final da década de 70, desenvolveu um instrumento para avaliar a institucionalização da gestão da qualidade nas empresas, a origem do conceito de maturidade. A proposta foi aplicada a outros setores funcionais, originando modelos de maturidade para avaliação da evolução das empresas em relação à gestão de outras áreas de negócio, como o PDP, e para orientar melhorias nestas áreas.
Diversos autores vêm refinando o conceito de maturidade para adequá-lo às necessidades de melhoria. Para Rozenfeld et al. (2006), a maturidade de processo é um indicador do quanto a empresa aplica melhores práticas. Para Dooley et al. (2001) e o CMMI (2002), a maturidade é o grau com que um processo ou atividade é institucionalizado e efetivado por toda a organização. Desta forma, o nível de maturidade é um indicativo da sofisticação, da estabilidade e frequencia com que práticas, técnicas e procedimentos padrão relacionados a uma área especifica são adotados (JUCÁ Jr.; AMARAL, 2005).

Fraser, Moultrie e Gregory (2002) observaram que as estruturas dos diversos modelos de maturidade diferenciaram-se ao longo do tempo. No entanto, os autores propuseram uma tipologia a partir da identificação de estruturas semelhantes, classificando os modelos de maturidade em três categorias: 1) grades de maturidade de processo; 2) modelos de capacidade de processo; e 3) modelos mistos.

As grades de maturidade são estruturas que apresentam uma descrição qualitativa das áreas estratégicas do processo. Geralmente utiliza-se uma grade para cada área de gestão ou área do conhecimento. Nessas grades, as práticas referentes às áreas são agrupadas e descritas em patamares de utilização desde o nível mais desagregado (não utilizadas) até o nível mais agregado (utilizadas plenamente).0Quadro2apresentaesquematicamente a estrutura das grades de maturidade.

Modelos de capacidade são constituídos a partir de uma estrutura mais robusta. De forma semelhante às grades de maturidade, os modelos de capacidade dividem o processo em áreas estratégicas; no entanto, os modelos de capacidade fixam práticas e objetivos a serem alcançados para cada área, em cada nível, ao invés da simples proposição do que deve ser feito. A Figura 1 apresenta a estrutura dos modelos de capacidade.

Modelos mistos reúnem características dos dois tipos mencionados anteriormente e constituem a forma mais simples de modelo de maturidade. Esses modelos são constituídos por um questionário sobre melhores práticas de desenvolvimento (FRASER; MOULTRIE; GREGORY, 2002). Os respondentes são solicitados a avaliar o desempenho da empresa em relação a práticas determinadas usando uma escala Likert. Conforme a pontuação, a empresa é classificada em uma escala de maturidade. Tais modelos proporcionam uma análise quantitativa elaborada a partir da percepção das pessoas que executam o processo, apresentando baixa complexidade de aplicação. 
0 Quadro 3 apresenta, em síntese, uma análise dos tipos de modelo de maturidade segundo tipologia proposta por Fraser Moultrie e Gregory (2002). Tais

\begin{tabular}{|c|c|c|c|}
\hline \multicolumn{4}{|c|}{ Modelos de capacidade de processo } \\
\hline \multicolumn{2}{|c|}{ Nivel de maturidade 1} & \multicolumn{2}{|c|}{ Nivel de maturidade $\mathrm{n}$} \\
\hline \multicolumn{2}{|c|}{ Áreas de processo 1.1} & \multicolumn{2}{|c|}{ Áreas de processo $n .1$} \\
\hline Objetivos & Práticas & Objetivos & Práticas \\
\hline \multicolumn{2}{|c|}{ Áreas de processo 1.2} & \multicolumn{2}{|c|}{ Áreas de processo n.2 } \\
\hline Objetivos & Práticas & Objetivos & Práticas \\
\hline \multicolumn{2}{|c|}{... } & \multicolumn{2}{|c|}{$\ldots$} \\
\hline \multicolumn{2}{|c|}{ Áreas de processo $1 . \mathrm{m}$} & \multicolumn{2}{|c|}{ Áreas de processo n.m } \\
\hline Objetivos & Práticas & Objetivos & Práticas \\
\hline
\end{tabular}

Figura 1. Estrutura esquemática de modelos de capacidade de processo.

Quadro 2. Estrutura esquemática de grade de maturidade.

\begin{tabular}{|c|c|c|c|c|c|}
\hline \multicolumn{6}{|c|}{ Grades de maturidade } \\
\hline & & \multicolumn{4}{|c|}{ Niveis de maturidade } \\
\hline & & $N_{1}$ & $\mathrm{~N}_{2}$ & $\ldots$ & $N_{n}$ \\
\hline \multirow{4}{*}{$\begin{array}{l}\text { Áreas de } \\
\text { processo } \\
\text { ou áreas de } \\
\text { conhecimento }\end{array}$} & $A_{1}$ & \multirow{4}{*}{\multicolumn{4}{|c|}{$\begin{array}{l}\text { Descrição qualitativa do domínio e/ou } \\
\text { características das áreas quanto ao nível } \\
\text { de utilização da mesma }\end{array}$}} \\
\hline & $\mathrm{A}_{2}$ & & & & \\
\hline & $\ldots$ & & & & \\
\hline & $A_{m}$ & & & & \\
\hline
\end{tabular}

modelos, de maneira geral, têm por objetivo verificar como as empresas realizam algumas práticas que consideram importantes para a boa execução do processo de gestão e orientação do esforço de melhoria. Essas práticas são apontadas por pesquisas que, ao longo das últimas décadas, tentam relacionar o bom desempenho de algumas empresas de destaque em áreas de negócio específicas com a maneira como realizam os processos de gestão de seu negócio.

Amaral e Rozenfeld (2007) mostram que os modelos de maturidade são eficientes para clarificar as motivações de melhoria fornecendo um ponto de partida para o processo de melhoria e determinando o seu escopo. No entanto, por se tratar de um instrumento de avaliação, os modelos de maturidade fazem um diagnóstico das melhores práticas utilizando como referência medida discreta e não contínua. Em outras palavras, eles avaliam se a empresa utiliza ou não a melhor prática, mas não mensuram o grau de utilização dessa técnica.

A análise e melhoria orientada que os modelos de maturidade podem proporcionar são positivas para as empresas. Porém, na maioria das vezes, os modelos existentes se restringem a apontar um índice ou valor de referência de maturidade, gerado a partir das melhores práticas de gestão já realizadas na empresa (SALVIANO, 2006). 0 valor numérico que indica o nível de maturidade da empresa, por outro lado, é bem aceito pelas esferas administrativas da organização para fins

Quadro 3. Análise dos tipos de modelos de maturidade.

\begin{tabular}{|c|c|c|c|}
\hline & Grades de maturidade & Modelos de capacidade & Modelos mistos \\
\hline Estrutura & $\begin{array}{l}\text { Desdobram o processo em áreas } \\
\text { do conhecimento e as descrevem } \\
\text { qualitativamente em função de níveis } \\
\text { de sofisticação }\end{array}$ & $\begin{array}{l}\text { Desdobram o processo em áreas do } \\
\text { conhecimento e determinam um conjunto } \\
\text { de objetivos e práticas a serem realizados } \\
\text { para cada nível de maturidade }\end{array}$ & $\begin{array}{l}\text { Desdobram o processo em áreas do } \\
\text { conhecimento, podendo desdobrar em } \\
\text { melhores práticas para avaliar o grau de } \\
\text { utilização em uma escala simples }\end{array}$ \\
\hline $\begin{array}{c}\text { Grau de } \\
\text { detalhamento } \\
\text { da melhoria } \\
\text { recomendada }\end{array}$ & $\begin{array}{l}\text { Detalhamento pobre das melhorias } \\
\text { a serem realizadas. Não fornecem } \\
\text { grau de detalhamento das Melhores } \\
\text { Práticas que devem ser implementadas } \\
\text { na empresa, pois a avaliação da } \\
\text { maturidade é realizada através de } \\
\text { descrições textuais de áreas do } \\
\text { conhecimento da maturidade }\end{array}$ & $\begin{array}{l}\text { Detalhamento mais minucioso do } \\
\text { processo. A análise é realizada em } \\
\text { função de objetivos e práticas para } \\
\text { cada área de conhecimento. Com isso é } \\
\text { possível perceber quais práticas devem } \\
\text { ser implementadas para atingir um grau } \\
\text { mais sofisticado de maturidade }\end{array}$ & $\begin{array}{l}\text { Detalhamentointermediário dasmelhorias } \\
\text { a serem realizadas. Oferecem uma } \\
\text { avaliação mais quantitativa de utilização } \\
\text { de práticas ou áreas consideradas. Com } \\
\text { isso é possivel perceber as práticas ou } \\
\text { áreas menos desenvolvidas, servindo para } \\
\text { focar o esforço de aperfeiçoamento }\end{array}$ \\
\hline $\begin{array}{l}\text { Formas de } \\
\text { aplicação }\end{array}$ & $\begin{array}{l}\text { Geralmente são aplicadas através de } \\
\text { questionários, workshopse auditorias } \\
\text { para avaliar qualitativamente o grau } \\
\text { de maturidade das empresas }\end{array}$ & $\begin{array}{l}\text { Utilizam questionários estruturados, } \\
\text { entrevistas, checklists, e análise de } \\
\text { documentos para avaliar qualitativa } \\
\text { e quantitativamente a realização dos } \\
\text { objetivos relacionados às práticas }\end{array}$ & $\begin{array}{l}\text { Utilizam questionários estruturados } \\
\text { aplicados na forma de entrevistas onde } \\
\text { a empresa é convidada a indicar em } \\
\text { uma escala simples o quanto utiliza as } \\
\text { práticas consideradas }\end{array}$ \\
\hline $\begin{array}{l}\text { Pontos } \\
\text { fortes }\end{array}$ & $\begin{array}{l}\text { Simplicidade de aplicação, construção } \\
\text { e detalhamento do escopo de } \\
\text { melhorias realizados pelos próprios } \\
\text { participantes do processo }\end{array}$ & $\begin{array}{l}\text { Detalhamento minucioso da sofisticação } \\
\text { do processo; avaliação realizada por } \\
\text { terceiro; o que minimiza a subjetividade } \\
\text { da análise (visão externa) }\end{array}$ & $\begin{array}{l}\text { Simplicidade de aplicação, fácil } \\
\text { visualização e entendimento do grau de } \\
\text { utilização das práticas do processo }\end{array}$ \\
\hline $\begin{array}{l}\text { Pontos } \\
\text { fracos }\end{array}$ & $\begin{array}{l}\text { Grau de detalhamento pobre, pode } \\
\text { sofrer influência dos participantes } \\
\text { dos workshops, aplicação rápida }\end{array}$ & $\begin{array}{l}\text { Complexo para ser aplicado, exigindo um } \\
\text { profissional proficiente na metodologia, } \\
\text { período de aplicação longo }\end{array}$ & $\begin{array}{l}\text { Grau de detalhamento das melhorias } \\
\text { intermediário, elevado grau de } \\
\text { subjetividade, os questionários precisam } \\
\text { ser longos para oferecer uma avaliação } \\
\text { abrangente }\end{array}$ \\
\hline
\end{tabular}


de controle, avaliação da concorrência, licitação e benchmarking entre empresas do mesmo setor e de setores diferentes.

Duas características podem ser apontadas nos modelos de maturidade tradicionais. Primeiramente, eles não se detêm na investigação das piores práticas ou problemas persistentes na gestão do PDP. Uma abordagem nesse sentido foi proposta por Echeveste (2003), que gerou um questionário de problemas típicos do PDP para analisar a situação presente da GPDP da empresa. Os problemas são facilmente lembrados pelos administradores, que têm relativa facilidade para abordá-los, o que nem sempre ocorre quando o objeto são as melhores práticas da empresa. Em segundo lugar, os modelos de maturidade tradicionais não auxiliam objetivamente a tomada de decisão sobre quais aspectos melhorar na GPDP e quais passos adotar, tática e operacionalmente, para implementação da melhoria da gestão. Essa decisão fica a cargo dos gestores do processo, que percebem de maneira subjetiva, a partir da sua expertise, a ordem de prioridade que devem atribuir às melhores práticas indicadas pelos modelos de maturidade tradicionais.

\section{Método proposto}

A estratégia de análise de maturidade proposta neste artigo relaciona periodicidade de ocorrência de problemas típicos da gestão do PDP com as melhores práticas para a sua administração, além de priorizar oportunidades de melhoria da GPDP. 0 método se divide em duas macroetapas (i) coleta de dados e análise de maturidade; e (ii) priorização das oportunidades de melhoria da GPDP, gerando um portfolio de melhorias. Essas duas se dividem em seis fases, conforme apresentado no Quadro 4.

Nota-se que as fases 3, 4 e 6 do Quadro 4 podem ser realizadas utilizando-se ferramentas da qualidade tradicionalmente existentes na empresa, enquanto as fases 1,2 e 5 empregam matrizes desenvolvidas especificamente para este método de análise de maturidade.

\subsection{Identificação da periodicidade de ocorrência de problemas no PDP}

Para identificar a frequência de ocorrência de problemas no PDP da empresa foi adaptado um questionário, idealizado por Echeveste (2003) e denominado pela autora "questionário de problemas típicos". Esse questionário vem sendo adaptado e utilizado pela pesquisadora e seu grupo de pesquisa como instrumento de diagnóstico da situação
Quadro 4. Método para análise de maturidade e priorização de melhorias na GPDP - fases e ferramentas sugeridas.

\begin{tabular}{|c|c|c|}
\hline Macroetapas & Fases & Ferramentas \\
\hline \multirow{3}{*}{$\begin{array}{l}\text { Coleta dos } \\
\text { dados e } \\
\text { análise de } \\
\text { maturidade }\end{array}$} & $\begin{array}{l}\text { 1. Identificação da } \\
\text { periodicidade de ocorrência } \\
\text { de problemas no PDP }\end{array}$ & $\begin{array}{l}\text { Questionário de } \\
\text { problemas típicos } \\
\text { adaptado }\end{array}$ \\
\hline & $\begin{array}{l}\text { 2. Análise dos graus de } \\
\text { maturidade e dos índices } \\
\text { de desenvolvimento }\end{array}$ & $\begin{array}{l}\text { Matriz de Índice } \\
\text { de Maturidade }\end{array}$ \\
\hline & $\begin{array}{l}\text { 3. Consolidação do conjunto } \\
\text { de oportunidades de } \\
\text { melhoria na gestão do PDP }\end{array}$ & $\begin{array}{l}\text { Ferramentas de } \\
\text { análise (exemplo: } \\
\text { BoxPlot) }\end{array}$ \\
\hline \multirow{3}{*}{$\begin{array}{l}\text { Geração do } \\
\text { portfolio de } \\
\text { melhorias }\end{array}$} & $\begin{array}{l}\text { 4. Determinação do peso } \\
\text { dos critérios e atributos } \\
\text { de priorização das } \\
\text { oportunidades de melhoria }\end{array}$ & $\begin{array}{l}\text { Ferramentas de } \\
\text { suporte à decisão } \\
\text { (exemplo: MAUT) }\end{array}$ \\
\hline & $\begin{array}{l}\text { 5. Priorização das } \\
\text { oportunidades de melhoria }\end{array}$ & $\begin{array}{l}\text { Matriz de } \\
\text { Priorização }\end{array}$ \\
\hline & $\begin{array}{l}\text { 6. Ranqueamento e } \\
\text { definição do portfolio de } \\
\text { oportunidades de melhoria }\end{array}$ & $\begin{array}{l}\text { Ferramentas } \\
\text { gráficas (exemplo: } \\
\text { gráfico de Pareto) }\end{array}$ \\
\hline
\end{tabular}

presente do PDP das empresas. Gusberti (2006), por exemplo, utilizou o questionário em intervenções no PDP de empresas farmacêuticas.

0 questionário original de Echeveste (2003) apresenta 81 problemas relacionados ao PDP, organizados em 12 grupos. Na presente aplicação, os problemas foram apresentados sem classificação por grupos. Em função da sobreposição apresentada pelos grupos de problemas (constataram-se problemas redundantes e/ou mal definidos, os quais foram eliminados do questionário), a oportunidade de condensar o instrumento foi avaliada, o que resultou numa lista com 52 problemas, disponível no Apêndice 1. Sua aplicação visa mensurar a frequência da ocorrência de problemas no cotidiano do desenvolvimento de produtos. Para tanto, utiliza-se uma escala contínua com 5 âncoras descritivas (Quadro 5). 0 valor $f_{j}$ designa a frequência declarada de ocorrência do $j$-ésimo $(j=1, \ldots, 52)$ problema na empresa. Recomenda-se a aplicação do questionário por uma equipe multidisciplinar de profissionais envolvidos em diferentes áreas da GPDP da empresa, utilizando a dinâmica de grupos focados, uma vez que $f_{j}$ é um indicador subjetivo da frequência de ocorrência dos problemas, informado por executantes do processo, e a construção deste índice demandar diferentes visões.

\subsection{Análise dos graus de maturidade e dos indices de desenvolvimento}

Os valores $f_{j}$ são usados como dados de entrada em uma estrutura denominada Matriz Índice de Maturidade (M). Nessa matriz, relacionam-se problemas típicos com melhores práticas para 
Quadro 5. Escala de frequência de ocorrência de problemas típicos.

\begin{tabular}{|l|l|}
\hline \multicolumn{2}{|c|}{ Frequência de ocorrência de problemas } \\
\hline 1 & Nunca ocorre \\
\hline 2 & Raramente ocorre (10 - 20\% dos projetos) \\
\hline 3 & Algumas vezes ocorre (20 - 50\% dos projetos) \\
\hline 5 & Ocorre frequentemente (50-90\% dos projetos) \\
\hline 6 & Quase sempre ocorre (90-100\% dos projetos) \\
\hline 8 & \\
\hline
\end{tabular}

desdobrar a frequência de ocorrência dos problemas em índices de desenvolvimento e em graus de maturidade que retratam o estado atual da GPDP na empresa. Para desdobrar a frequência de ocorrência em índices e graus de maturidade, a matriz M é composta de uma Referência de Melhores Práticas (RMP), de uma matriz contendo os relacionamentos $r_{\text {iij }}$ e de uma série de indicadores, ilustrados no Quadro 6 e descritos a seguir.

\subsubsection{Referência de Melhores Práticas (RMP)}

A RMP é uma estrutura hierárquica onde melhores práticas do PDP são agrupadas em 30 habilidades, as habilidades em 10 áreas de conhecimento e as áreas de conhecimento em 3 áreas de GPDP (Quadro 7)”. A RMP foi construída a partir (i) de estudos de melhores práticas publicados pelo PDMA (Product Development and Management Institute) e pelo APQC (American Productive and Quality Control), (ii) de guias de melhores práticas (PDMABOK, 2003; PROJECT MANAGEMENT INSTITUTE, 2004) e (iii) de modelos de referência para o PDP (ROMANO, 2003; PAULA; RIBEIRO, 2007; ROZENFELD et al., 2006).

A RMP descreve a gestão do PDP em cinco níveis de desdobramento, conforme apresentado no Quadro 7. As áreas de gestão e do conhecimento que compõem a RMP estão descritas textualmente no Apêndice 2, para fins de simplificação. 0 Quadro 7 apresenta com maior fidelidade a abrangência da RMP, que inclui melhores práticas relacionadas com gestão estratégica, melhores práticas relacionadas com fases, atividades e portais do PDP e melhores práticas relacionadas com aspectos de suporte às duas áreas anteriormente citadas.

\subsubsection{Matriz de Relacionamentos}

A matriz de relacionamentos é o principal elemento da matriz $\mathrm{M}$ e uma das principais contribuições do método aqui proposto. Ela evidencia as relações entre os problemas listados
Quadro 6. Matriz Índice de Maturidade.

\begin{tabular}{|c|c|c|c|c|c|c|c|c|c|c|}
\hline \multicolumn{11}{|c|}{ Matriz Índice de Maturidade (M) } \\
\hline \multicolumn{3}{|c|}{ RMP } & \multicolumn{4}{|c|}{$\begin{array}{l}\text { Questionário de } \\
\text { problemas PDP }\end{array}$} & \multirow[b]{3}{*}{ 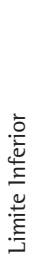 } & \multirow[b]{3}{*}{ 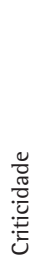 } & \multirow[b]{3}{*}{ 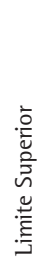 } & \multirow[b]{3}{*}{ 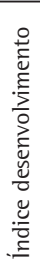 } \\
\hline & & & $P_{1}$ & $\mathrm{P}_{2}$ & $\ldots$ & $P_{52}$ & & & & \\
\hline \multirow{6}{*}{ 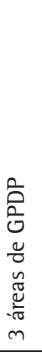 } & \multirow{6}{*}{ 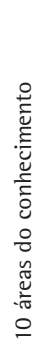 } & $\begin{array}{l}\text { Melhores } \\
\text { práticas }\end{array}$ & $f_{1}$ & $f_{2}$ & $\ldots$ & $f_{52}$ & & & & \\
\hline & & $\mathrm{MP}_{1}$ & \multirow{5}{*}{\multicolumn{4}{|c|}{$r_{\mathrm{ij}}$}} & $I_{1}$ & $c r_{1}$ & $I s_{1}$ & $I D_{1}$ \\
\hline & & $\mathrm{MP}_{2}$ & & & & & $I_{2}$ & $\mathrm{Cr}_{2}$ & $I_{2}$ & $I D_{2}$ \\
\hline & & $\ldots$ & & & & & $\ldots$ & $\ldots$ & $\ldots$ & $\ldots$ \\
\hline & & $\ldots$ & & & & & $\ldots$ & $\ldots$ & $\ldots$ & $\ldots$ \\
\hline & & $\mathrm{MP}_{95}$ & & & & & $I_{95}$ & $c r_{95}$ & $I s_{95}$ & $1 D_{95}$ \\
\hline$N M$ & $N M_{\mathrm{g}}$ & $\begin{array}{l}\text { Importância } \\
\text { dos } \\
\text { problemas }\end{array}$ & $i p_{1}$ & $i p_{2}$ & $\cdots$ & $i p_{52}$ & & & & \\
\hline
\end{tabular}

no questionário de problemas típicos e as melhores práticas listadas na RMP. Tais relações foram determinadas por especialistas por meio de grupos focados.

Sete grupos, organizados de forma a compreender pelo menos três especialistas e formados de acordo com especialidade e disponibilidade dos pesquisadores, foram consultados relativamente às seguintes áreas de conhecimento: (1) estratégia da corporação; (2) estratégia do projeto/produto; (3) pesquisa de mercado e consumidor; (4) gestão de portfolio e cultura e clima para a inovação; (5) processo sistematizado; (6) portais de aprovação, métricas e avaliação de desempenho; e (7) pessoas e organização e estruturação do PDP. A maioria dos especialistas participou de mais de um grupo.

Para cada grupo focado foi planejado um roteiro de apresentação da pesquisa. A primeira parte do roteiro destinou-se à apresentação geral da pesquisa, com a descrição das áreas do conhecimento que constituem a estrutura de boas práticas e 0 detalhamento dos objetivos do grupo focado. A segunda parte detalhou as habilidades e as melhores práticas que constituiam a área de conhecimento a ser discutida. A terceira parte apresentou a lógica de determinação dos relacionamentos e a escala de sua aferição.

Os especialistas responderam à seguinte pergunta: "Qual a contribuição da adoção plena da melhor prática $i$ na redução da periodicidade de ocorrência do problema $j$ ?" A resposta para a pergunta estabelecia o relacionamento $r_{i j}$ entre boa prática $i$ e o problema $j$. Os respondentes utilizaram uma escala contínua de 9 pontos, onde 0 sinalizava a inexistência de relação e 9, uma relação de intensidade máxima. 
Quadro 7. Referência de melhores práticas agrupadas por habilidade, área de conhecimento e área de GPDP (visão parcial).

\begin{tabular}{|c|c|c|c|c|}
\hline $\begin{array}{l}\text { Áreas } \\
\text { de } \\
\text { GPDP }\end{array}$ & $\begin{array}{l}\text { Áreas de } \\
\text { conheci- } \\
\text { mento }\end{array}$ & Habilidades & Melhores práticas & Descrições \\
\hline 3 & 10 & 30 & 95 & 302 \\
\hline \multirow{17}{*}{ 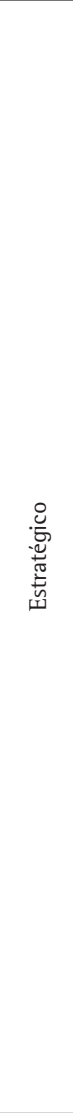 } & \multirow{5}{*}{$\begin{array}{l}\text { Estratégia da } \\
\text { corporação }\end{array}$} & \multirow{2}{*}{$\begin{array}{l}\text { Realizar análises externas para } \\
\text { detalhar a oportunidade } \\
\text { (inovação, desenvolvimento e } \\
\text { crescimento) }\end{array}$} & Analisar as forças macroambientais & $\begin{array}{l}\text { Realizar análise } \\
\text { econômico-financeira } \\
\text { da oportunidade }\end{array}$ \\
\hline & & & Analisar forças microambientais & $\begin{array}{c}\text { Realizar análise tecnológica } \\
\text { da oportunidade }\end{array}$ \\
\hline & & $\begin{array}{c}\text { Realizar análises internas para } \\
\text { detalhar a oportunidade }\end{array}$ & $\begin{array}{c}\text { Analisar competência econômico-financeira } \\
\text { da empresa (...continua) }\end{array}$ & (...continua) \\
\hline & & $\begin{array}{l}\text { Estabelecer metas que espelhem a missão } \\
\text { e valores da organização para o negócio }\end{array}$ & $\begin{array}{c}\text { Definir objetivos para a corporação } \\
\text { (...continua) }\end{array}$ & (...continua) \\
\hline & & Implementar as estratégias & $\begin{array}{c}\text { Organizar-se para realizar os objetivos } \\
\text { estratégicos (...continua) }\end{array}$ & (...continua) \\
\hline & \multirow{6}{*}{$\begin{array}{l}\text { Estratégia } \\
\text { do projeto/ } \\
\text { produto }\end{array}$} & Definir métricas & $\begin{array}{l}\text { Definir métricas para gestão do negócio } \\
\text { (...continua) }\end{array}$ & (...continua) \\
\hline & & $\begin{array}{l}\text { Clarificar as necessidades a serem atendidas } \\
\text { através dos benefícios do produto }\end{array}$ & $\begin{array}{c}\text { Levantar informações do novo produto } \\
\text { (...continua) }\end{array}$ & (...continua) \\
\hline & & $\begin{array}{l}\text { Analisar competências internas para } \\
\text { atender a necessidade do projeto/produto }\end{array}$ & $\begin{array}{l}\text { Analisar competências econômico- } \\
\text { financeiras da empresa para o projeto } \\
\text { (...continua) }\end{array}$ & (...continua) \\
\hline & & Estabelecer metas para o projeto/produto & Definir objetivos para o projeto (...continua) & (...continua) \\
\hline & & $\begin{array}{c}\text { Definir métricas de controle e } \\
\text { acompanhamento do projeto/produto }\end{array}$ & $\begin{array}{l}\text { Definir métricas de controle do projeto } \\
\text { (...continua) }\end{array}$ & (...continua) \\
\hline & & ldentificar personagens & $\begin{array}{l}\text { Identificar os principais interessados no } \\
\text { projeto/produto (...continua) }\end{array}$ & (...continua) \\
\hline & \multirow{2}{*}{$\begin{array}{l}\text { Gestão de } \\
\text { portfólio }\end{array}$} & Formalizar a gestão de portfólio & $\begin{array}{c}\text { Utilizar uma metodologia formal de gestão } \\
\text { de portfólio (...continua) }\end{array}$ & (...continua) \\
\hline & & $\begin{array}{l}\text { Operacionalizar a seleção e priorização } \\
\text { dos projetos }\end{array}$ & $\begin{array}{l}\text { Utilizar critérios claros para seleção e } \\
\text { priorização do projeto (...continua) }\end{array}$ & (...continua) \\
\hline & \multirow{4}{*}{$\begin{array}{l}\text { Pesquisa de } \\
\text { mercado e } \\
\text { consumidor }\end{array}$} & Adquirir informações do mercado & $\begin{array}{l}\text { Vigilância tecnológica e mercadológica } \\
\text { (...continua) }\end{array}$ & (...continua) \\
\hline & & Analisar as informações do mercado & Identificar oportunidades (...continua) & (...continua) \\
\hline & & Determinar o mix de marketing & $\begin{array}{l}\text { Determinar variáveis relativas ao produto } \\
\text { (...continua) }\end{array}$ & (...continua) \\
\hline & & Realizar teste de mercado & Validar requisitos (...continua) & (...continua) \\
\hline \multirow{5}{*}{ 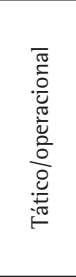 } & \multirow{3}{*}{$\begin{array}{c}\text { Processo } \\
\text { sistematizado }\end{array}$} & Sistematizar um PDP & $\begin{array}{c}\text { Elaborar um processo formal do PDP } \\
\text { (...continua) }\end{array}$ & (...continua) \\
\hline & & Executar as fases do PDP & $\begin{array}{c}\text { Planejamento estratégico do produto } \\
\text { (...continua) }\end{array}$ & (...continua) \\
\hline & & Envolver setores & Definir a participação dos setores (...continua) & (...continua) \\
\hline & \multirow{2}{*}{$\begin{array}{l}\text { Portais de } \\
\text { aprovação }\end{array}$} & Realizar gates de aprovação & Realizar gates gerenciais (...continua) & (...continua) \\
\hline & & Documentar as fases do DP & $\begin{array}{c}\text { Documentar fase: Planejamento estratégico } \\
\text { do produto (...continua) }\end{array}$ & (...continua) \\
\hline \multirow{10}{*}{ 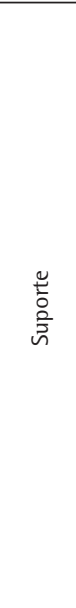 } & \multirow{3}{*}{ Pessoas } & Gerenciamento dos recursos humanos & Planejar recursos humanos (...continua) & (...continua) \\
\hline & & $\begin{array}{l}\text { Determinar formalmente a } \\
\text { participação no DP }\end{array}$ & $\begin{array}{l}\text { Determinar formalmente os personagens do } \\
\text { processo (...continua) }\end{array}$ & (...continua) \\
\hline & & Comprometer recursos humanos & $\begin{array}{l}\text { Comprometer recursos para o projeto de DP } \\
\text { (...continua) }\end{array}$ & (...continua) \\
\hline & \multirow{3}{*}{$\begin{array}{l}\text { Organização } \\
\text { e } \\
\text { estruturação } \\
\text { para PDP }\end{array}$} & $\begin{array}{l}\text { Comprometer recursos para o } \\
\text { trabalho de DP }\end{array}$ & $\begin{array}{c}\text { Garantir a suficiência de recursos (humanos, } \\
\text { tecnológicos, equipamentos, } \\
\text { de infraestrutura e outros) (...continua) }\end{array}$ & (...continua) \\
\hline & & Formalizar sistema de suporte ao DP & Utilizar canais de comunicação (...continua) & (...continua) \\
\hline & & Organizar o trabalho de DP & $\begin{array}{c}\text { Adotar práticas de organização da equipe } \\
\text { de projeto (...continua) }\end{array}$ & (...continua) \\
\hline & \multirow{2}{*}{$\begin{array}{l}\text { Cultura e } \\
\text { clima para } \\
\text { inovação }\end{array}$} & Incentivar o trabalho de DP & Prêmios de incentivo (...continua) & (...continua) \\
\hline & & Treinar/conscientizar RH & $\begin{array}{c}\text { Reconhecer a importância das fases iniciais } \\
\text { (...continua) }\end{array}$ & (...continua) \\
\hline & \multirow{2}{*}{$\begin{array}{l}\text { Métricas e } \\
\text { avaliação de } \\
\text { desempenho }\end{array}$} & $\begin{array}{l}\text { Formalizar um sistema de avaliação } \\
\text { de desempenho }\end{array}$ & $\begin{array}{l}\text { Utilizar um sistema formal de avaliação } \\
\text { de desempenho (...continua) }\end{array}$ & (...continua) \\
\hline & & $\begin{array}{c}\text { Avaliar/acompanhar o desempenho } \\
\text { do projeto/produto }\end{array}$ & $\begin{array}{c}\text { Avaliar/acompanhar o desempenho } \\
\text { do projeto (...continua) }\end{array}$ & (...continua) \\
\hline
\end{tabular}


As reuniões para preenchimento da matriz de relacionamentos tiveram duração média de 1 h30min. Foram realizadas 44 entrevistas com especialistas, como resumido na Tabela 1. No total, 4.940 relações foram analisadas. A matriz resultante da pesquisa está disponível no apêndice eletrônico (https://spreadsheets.google.com/ccc?k ey=0AsVVSr93P98idDIXS0tFNINfVFpLZWtremQzR 2pERVE\&hl=en).

A matriz de relacionamentos é a base para determinação do grau de maturidade de cada área do conhecimento na GPDP. Em aplicações do método proposto, essa matriz permanece inalterada; somente a coleta de informações sobre a frequência de ocorrência de problemas no PDP é necessária. A determinação dos graus de maturidade utiliza os indicadores descritos a seguir.

Frequência de ocorrência dos problemas $\left(f_{j}\right)-$ informada pela empresa através do questionário de problemas típicos.

Impacto do problema $j\left(i p_{j}\right)$ - representa a relevância do problema para a GPDP, considerando o somatório das intensidades de relacionamento do problema com cada prática, através da Equação 1:

$i p_{j}=\sum_{i=1}^{95} r_{i j}, j=1, \ldots, 52$

Limite superior da prática $i\left(l s_{i}\right)$ - representa o pior cenário de ocorrência da prática $i$ na GPDP, obtido através da soma dos produtos de três termos: os relacionamentos envolvendo aquela prática, o índice de impacto dos problemas e a frequência mais elevada de ocorrência dos problemas $\left(f_{j}=9\right)$ ; isto é (Equação 2):

$l s_{i}=\sum_{j=1}^{52} r_{i j} \times i p_{j} \times 9, i=1, \ldots, 95$

Limite inferior da prática $i\left(l_{i}\right)$ - 'representa o melhor cenário de ocorrência da prática $i$ na GPDP, obtido através de uma expressão análoga à equação (2), porém considerando a frequência menos elevada de ocorrência dos problemas $\left(f_{j}=1\right)$ ; isto é (Equação 3):

$l i i_{i}=\sum_{j=1}^{52} r_{i j} \times i p_{j} \times 1, i=1, \ldots, 95$

Criticidade da prática $i\left(c r_{i}\right)$ - representa a situação em que a prática se encontra atualmente na empresa, dada pela Equação 4:

$c r_{i}=\sum_{j=1}^{52} r_{i j} \times i p_{j} \times f_{j}, i=1, \ldots, 95$

Índice de desenvolvimento da melhor prática $i$ $\left(I D_{i}\right)$ - representa o grau de desenvolvimento da prática, em uma escala de 0 a 10, onde 10 é o estado mais desenvolvido da prática (Equação 5):

$I D_{i}=\frac{c r_{i}-l i_{i}}{l s_{i}-l i_{i}} \times 10, i=1, \ldots, 95$

Índice de desenvolvimento da área do conhecimento $k\left(I D_{k}\right)$ - representa o grau de desenvolvimento da $k$-ésima área do conhecimento, sendo dado pela média geométrica dos $I D_{i}$ das práticas contidas na área; isto é (Equação 6):

$I D_{k}=\left(\prod_{i e k} I D_{i}\right)^{1 / \Sigma i}, k=1, \ldots, 10$

Grau de maturidade da área do conhecimento $k$ $\left(N M_{k}\right)$ - representa o grau de sofisticação da GPDP, sendo função de $I D_{k}$ categorizada pelos intervalos propostos na Tabela 2 .

Grau de maturidade da área de gestão $g(N M g)$ - representa o grau de maturidade da área de gestão $g[g=E$ (Estratégica), TO (Tática-Operacional), $S$ (de Suporte)], dado pela Equação 7:

$N M g=\min _{\text {keg }}\left(N M_{k}\right)$

Grau de desenvolvimento global na GPDP (NM) - corresponde ao pior desempenho da empresa relativamente aos indicadores $N M_{g}$; isto é (Equação 8):

$N M=\min _{\text {todo } g}\left(N M_{g}\right)$

Tabela 1. Número de entrevistas com grupos focados por área do conhecimento.

\begin{tabular}{ccc}
\hline Grupo & Especialidade & $\begin{array}{c}\text { Total de } \\
\text { entrevistas }\end{array}$ \\
\hline 1 & Estratégia da corporação & 7 \\
2 & Estratégia do projeto/produto & 7 \\
3 & Pesquisa de mercado e consumidor & 6 \\
4 & Gestão de porfólio e Cultura e clima & 7 \\
5 & para a inovação & 5 \\
6 & Processo sistematizado & 6 \\
7 & $\begin{array}{c}\text { Portais de aprovação e Métricas e } \\
\text { avaliação de desempenho }\end{array}$ & 6 \\
\hline
\end{tabular}

Tabela 2. Graus de desenvolvimento das áreas de conhecimento como função do $I D_{k}$.

\begin{tabular}{cc}
\hline Níveis de Maturidade & $\begin{array}{c}\text { Faixa de Domínio de Índice } \\
\text { de Desenvolvimento }\end{array}$ \\
\hline 1 & $0|-| 2,50$ \\
2 & $2,50-\mid 5,00$ \\
3 & $5,00-\mid 7,25$ \\
4 & $7,25-\mid 9,50$ \\
5 & $9,50-\mid 10,00$ \\
\hline
\end{tabular}




\subsection{Consolidação do conjunto de oportunidades de melhoria}

Uma vez desdobrada a frequência de ocorrência dos problemas típicos da GPDP em índices e em graus de maturidade, pode-se analisar o desenvolvimento das áreas de conhecimento e de gestão do PDP. Como a institucionalização da GPDP na empresa pressupõe uma evolução harmônica das áreas de gestão Estratégica, Tática-Operacional e de Suporte, o pressuposto deste método de análise é enfatizar a redução dos problemas típicos nas áreas que apresentarem os menores índices de desenvolvimento. Essas áreas são denominadas áreas críticas; para examinar o seu comportamento, recomenda-se utilizar ferramentas estatísticas de análise, como, por exemplo, o BoxPlot. Através dessa ferramenta é possível perceber a amplitude de distribuição dos valores de $I D$, reconhecendo comportamentos atípicos e possíveis tendências nos valores. As melhores práticas contidas nas áreas de conhecimento críticas são consideradas oportunidades de projeto de melhoria para a GPDP. Assim, as áreas críticas são exploradas com intuito de determinar um portfolio de oportunidades de melhorias adequado ao perfil competitivo da empresa, na segunda macroetapa do método.

\subsection{Determinação do peso dos critérios e atributos de priorização}

$\mathrm{Na}$ primeira fase da segunda macroetapa, o grupo de pessoas envolvido na análise de maturidade é solicitado a estabelecer o perfil a ser adotado na tomada de decisão acerca das oportunidades de melhoria identificadas na macroetapa anterior. 0 perfil de tomada de decisão é formado pelo peso de importância atribuído a critérios e atributos que serão utilizados para comparar as oportunidades de melhoria. Esses critérios e atributos sugeridos oferecem oportunidade de tornar orgânica a priorização das melhorias, pois permitem à empresa realizar os trade-offs de acordo com suas caracteristicas culturais, organizacionais e com a urgência de melhoria.

Para avaliar os trade-offs entre os atributos, recomenda-se a utilização de ferramentas de suporte à tomada de decisão em ambientes multicritérios. Para maximizar a satisfação da gerência em relação à priorização das oportunidades de melhoria, foi construída uma estrutura multiatributos (Multiattribute Utility - MAUT) para ponderação das oportunidades de melhoria, conforme o Quadro 8. 0 primeiro critério avalia a
Quadro 8. Estrutura multiatributos - MAUT.

\begin{tabular}{|c|c|c|c|c|}
\hline \multicolumn{5}{|c|}{ Perfil de descisão para priorização dos projetos de melhoria } \\
\hline Objetivo & Critérios & Atributos & Peso & $p a_{n}$ \\
\hline \multirow{8}{*}{$\begin{array}{l}\text { Priorizar } \\
\text { sugestões } \\
\text { de } \\
\text { melhoria }\end{array}$} & \multirow{3}{*}{$\begin{array}{l}\text { Importância } \\
\text { da alternativa } \\
\text { de melhoria }\end{array}$} & $\begin{array}{c}\text { Realização das metas } \\
\text { estratégicas }\end{array}$ & & \\
\hline & & $\begin{array}{c}\text { Eliminação dos } \\
\text { pontos fracos de PDP }\end{array}$ & & \\
\hline & & $\begin{array}{c}\text { Impacto na estrutura } \\
\text { organizacional }\end{array}$ & & \\
\hline & \multicolumn{2}{|c|}{ Importância do primeiro critério } & & \\
\hline & \multirow{3}{*}{$\begin{array}{l}\text { Esforço da } \\
\text { alternativa de } \\
\text { melhoria }\end{array}$} & Risco técnico & & \\
\hline & & $\begin{array}{l}\text { Necessidade de RH } \\
\text { qualificado }\end{array}$ & & \\
\hline & & $\begin{array}{l}\text { Necessidade de } \\
\text { Investimento }\end{array}$ & & \\
\hline & \multicolumn{2}{|c|}{ 1mportância do segundo critério } & & \\
\hline
\end{tabular}

oportunidade de melhoria em relação à importância de implementação (características relativas à contribuição que a melhoria oferece à empresa); o segundo critério avalia a oportunidade em relação ao esforço de implementação (características relativas à complexidade de implementação da melhoria). 0 MAUT permite estruturar problemas complexos em uma estrutura hierárquica para avaliar subjetivamente um grande número de fatores qualitativos e quantitativos (MIN, 1994).

A partir da estrutura hierárquica, o grupo de pessoas envolvido na melhoria é convidado a atribuir importância aos atributos e aos critérios, consensualmente, em uma escala de 0 a 100 , sendo 100 o valor máximo de importância. As importâncias declaradas são então reescritas em termos percentuais, gerando os pesos $\left(p a_{n}, n=1, \ldots, N\right) .0$ conjunto dos $p a_{n}$ constitui o perfil de tomada de decisão do grupo de avaliadores.

\subsection{Priorização das oportunidades de melhoria}

Nesta fase do método, exploram-se as oportunidades de melhorias contidas nas áreas críticas levantadas na matriz M. Para tanto, utiliza-se uma Matriz de Priorização $(P)$, apresentada no Quadro 9. Nas linhas da matriz são listadas as melhores práticas avaliadas na matriz $\mathrm{M}$, além de seus valores calculados de criticidade $\left(c r_{i}\right)$. Nas colunas da matriz são listados os critérios de priorização das oportunidades de melhoria, identificados e ponderados na etapa 3.4. 0 grupo de analistas é solicitado a determinar o grau de atendimento das melhores práticas aos critérios de priorização, expresso pelo indicador $p d_{i n}(i=1, \ldots, I ; n=1, \ldots, N)$. Esse indicador é construído através de uma discussão dirigida onde os membros do grupo de melhoria devem responder 
Quadro 9. Matriz P de priorização.

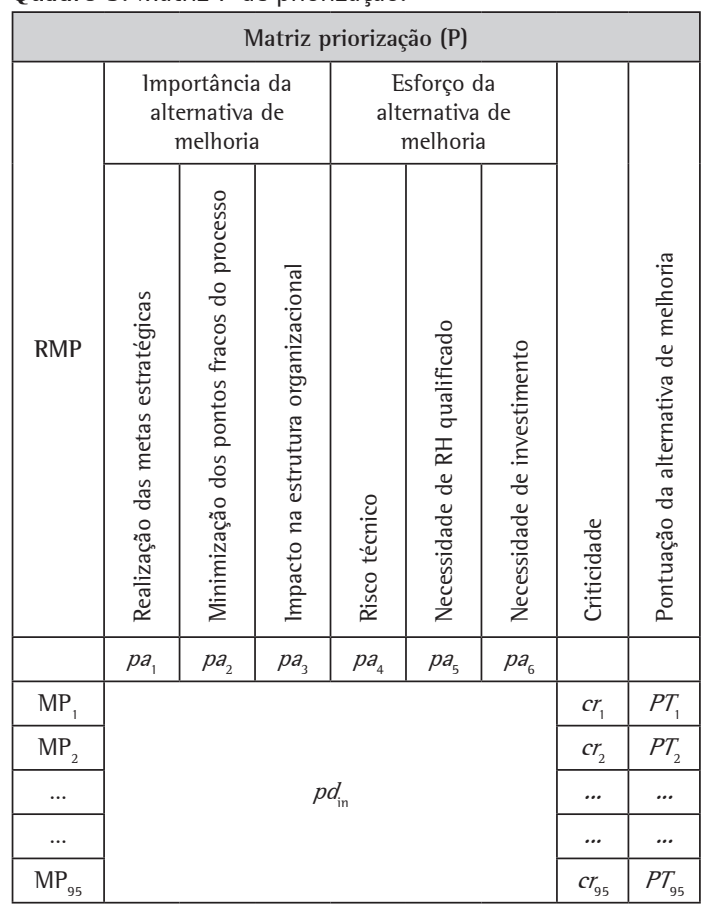

consensualmente as seguintes perguntas: (1) para atribuição do critério Importância da Alternativa de Melhoria: "Qual a importância da oportunidade de melhoria $i$ na realização do atributo $n$ ?"; e (2) para atribuição do critério Esforço da Alternativa de Melhoria: "Qual a necessidade da alternativa de melhoria $i$ em relação ao atributo $n$ ?" Essa avaliação é realizada utilizando uma escala geométrica de três valores: 9 (relacionamento forte), 3 (relacionamento moderado) e 1 (relacionamento fraco). A ausência de relação é sinalizada pelo valor 0 . A pontuação final de cada oportunidade de melhoria $\left(P T_{i}\right)$ é dada pela Equação 9:

$$
P T_{i}=\sum_{n=1}^{N}\left(p d_{i n} \times p a_{n}\right) \times c r_{i}, i=1, \ldots, I
$$

A relação da importância das atribuições $\left(p a_{n}\right)$ com a forma como a empresa percebe o seu atendimento pelas oportunidades de melhoria $\left(p d_{\text {in }}\right)$ demonstra a expectativa da empresa em relação a cada oportunidade de melhoria. Essa expectativa não é suficiente para direcionar a tomada de decisão no que se refere à necessidade de melhoria da GPDP. Assim, torna-se interessante balizar este relacionamento com a criticidade de cada oportunidade de melhoria obtida em função da frequência de ocorrência dos problemas no cotidiano da empresa, o que se reflete na pontuação da oportunidade de melhoria $\left(P T_{\mathrm{i}}\right)$.

\subsection{Ranqueamento e definição do portfolio de oportunidades de melhorias}

$\mathrm{Na}$ última fase do método ocorre $\mathrm{o}$ ordenamento dos valores de $P T_{i}$ e a definição do portfolio das oportunidades de melhoria. Para auxiliar na visualização das práticas consideradas mais importantes e facilitar a tomada de decisão, sugere-se utilizar ferramentas gráficas, tais como o gráfico de Pareto.

\section{Estudo de caso}

0 estudo de caso foi realizado em uma empresa de porte médio do setor de desenvolvimento de software. A empresa (Empresa D), localizada na região Sul do Brasil, desenvolve bens de capital (aplicativos computacionais para controle de frotas de caminhões e automóveis relativamente a consumo de combustível, quilometragem, manutenções etc.) e serviços (customização e implantação dos aplicativos). Os itens subsequentes descrevem as fases do método proposto aplicadas ao estudo de caso.

\subsection{Fase 1: Identificação da frequência de ocorrência de problemas típicos}

0 questionário de problemas típicos foi respondido por uma equipe multidisciplinar composta pelo superintendente de produtos, dois gerentes de projeto, um analista de produto e um analista de marketing. 0 grupo foi convidado a determinar consensualmente a frequência de ocorrência dos problemas típicos no cotidiano da empresa através de uma discussão dirigida, utilizando a dinâmica de moderação de grupos focados, onde o problema seguinte só era abordado depois de finda a discussão sobre o problema anterior. 0 resultado desta seção está apresentado no Apêndice 1. Durante a aplicação do questionário de problemas, os respondentes fizeram observações que foram compiladas no Quadro 10 e que dizem respeito à GPDP da empresa.

\subsection{Fase 2: Análise dos graus de maturidade e dos índices de desenvolvimento}

A análise da frequência de ocorrência dos problemas apontados pela Empresa D indicou que ela se encontra no grau 2 de maturidade da gestão do PDP, conforme apresentado na Tabela 3. Observando-se a maturidade das áreas de gestão do 
Quadro 10. Observações realizadas a respeito da GPDP da Empresa D.

\begin{tabular}{|c|c|}
\hline \multicolumn{2}{|r|}{ Empresa D } \\
\hline $\begin{array}{l}\text { Diretrizes estratégicas } \\
\text { do produto }\end{array}$ & $\begin{array}{l}\text { A empresa declara as estratégias corporativas que são desdobradas informalmente nas linhas de produtos. A alta } \\
\text { administração comunica diretamente seus objetivos aos colaboradores e participa constantemente no PDP. }\end{array}$ \\
\hline $\begin{array}{l}\text { Gerenciamento } \\
\text { do portfólio }\end{array}$ & $\begin{array}{l}\text { Não é utilizado um processo formal de gestão de portfólio. A maior parte dos projetos apresenta-se alinhadas com } \\
\text { as estratégias e com a capacidade da empresa. }\end{array}$ \\
\hline $\begin{array}{l}\text { Método de gestão } \\
\text { de projetos }\end{array}$ & $\begin{array}{l}\text { Existe um método de gestão de projetos com forte ênfase no planejamento, mas a implementação é recente e } \\
\text { ainda existe resistência a sua utilização. As fases do pré-desenvolvimento não estão claramente definidas. }\end{array}$ \\
\hline $\begin{array}{l}\text { Pontos de } \\
\text { controle }\end{array}$ & $\begin{array}{l}\text { Existem pontos de controle no final de cada etapa: um comitê de produto é responsável pelas decisõese alocação } \\
\text { de recursos, porém não existe preocupação de documentar as decisões e lições aprendidas. }\end{array}$ \\
\hline $\begin{array}{l}\text { Controle e } \\
\text { acompanhamento } \\
\text { do projeto }\end{array}$ & $\begin{array}{l}\text { A análise do desempenho do projeto e o acompanhamento do mesmo não são realizados sistematicamente. Não } \\
\text { são utilizadas métricas para avaliar o andamento e o controle é realizado apenas nos pontos de controle, ao final } \\
\text { de cada etapa. }\end{array}$ \\
\hline $\begin{array}{l}\text { Utilização de ferramentas } \\
\text { de auxílio ao projeto }\end{array}$ & $\begin{array}{l}\text { São utilizadas ferramentas de projeto de software. No entanto, as ferramentas de gestão do projeto ainda não } \\
\text { estão totalmente integradas e cada setor é responsável por registrar o seu trabalho no projeto. }\end{array}$ \\
\hline $\begin{array}{l}\text { Sistema de informação } \\
\text { e comunicação }\end{array}$ & $\begin{array}{l}\text { A empresa usa a internet para se comunicar com os envolvidos no projeto e reuniões para discutir as atividades dos } \\
\text { mesmos. Entretanto, essa não é uma prática sistematizada. Ela ocorre principalmente para solução de problemas } \\
\text { e conflitos. Não há preocupação com o registro dessas reuniões. }\end{array}$ \\
\hline $\begin{array}{l}\text { Aperfeiçoamento do } \\
\text { pessoal envolvido }\end{array}$ & $\begin{array}{l}\text { A empresa preocupa-se com o desenvolvimento das habilidades técnicase gerenciais dos envolvidos. Recentemente } \\
\text { foi realizado um curso in company de gestão de projetos. A empresa não oferece prêmios de incentivo financeiro } \\
\text { se nem estimula o trabalho criativo. }\end{array}$ \\
\hline $\begin{array}{l}\text { Envolvimento } \\
\text { multifuncional }\end{array}$ & $\begin{array}{l}\text { É utilizada uma estrutura funcional com horizontalização dasfunções. A alta administração, marketing, vendas e } \\
\text { suporte ao cliente participam desde o planejamento do projeto, no entanto, a área produtiva não tem proximidade } \\
\text { com as demais áreas. }\end{array}$ \\
\hline $\begin{array}{l}\text { Orientação para } \\
\text { o mercado }\end{array}$ & $\begin{array}{l}\text { Existe uma preocupação constante e focalizada na análise da concorrência, porém, a empresa não tem uma política } \\
\text { definida de pesquisa de mercado. Procura-se envolver os clientes no detalhamento do projeto, principalmente pelo } \\
\text { grau de customização dos produtos/serviços oferecidos. Há monitoração dos produtos no mercado, mas de forma } \\
\text { não sistemática. }\end{array}$ \\
\hline
\end{tabular}

Tabela 3. Matriz índice de maturidade (M) e áreas críticas de gestão do PDP da Empresa D.

\begin{tabular}{|c|c|c|c|c|}
\hline Área & $\begin{array}{c}\text { Grau de } \\
\text { maturidade }\end{array}$ & Subárea & $I D$ & NM \\
\hline \multirow[t]{4}{*}{ Estratégico } & 3 & $\begin{array}{l}\text { Estratégia de } \\
\text { corporação }\end{array}$ & 6,44 & 3 \\
\hline & & $\begin{array}{c}\text { Estratégia de } \\
\text { projeto/produto }\end{array}$ & 6,16 & 3 \\
\hline & & Gestão de portfólio & 6,73 & 3 \\
\hline & & $\begin{array}{l}\text { Pesquisa de } \\
\text { mercado e } \\
\text { consumidor }\end{array}$ & 6,27 & 3 \\
\hline \multirow[t]{2}{*}{$\begin{array}{l}\text { Tático- } \\
\text { operacional }\end{array}$} & 2 & $\begin{array}{c}\text { Processo } \\
\text { sistematizado }\end{array}$ & 5,87 & 3 \\
\hline & & $\begin{array}{l}\text { Portais de } \\
\text { aprovação }\end{array}$ & 4,41 & 2 \\
\hline \multirow[t]{4}{*}{ Suporte } & 3 & Pessoas & 5,12 & 3 \\
\hline & & $\begin{array}{c}\text { Organização e } \\
\text { estruturação para } \\
\text { o PDP }\end{array}$ & 5,37 & 3 \\
\hline & & $\begin{array}{l}\text { Cultura e clima } \\
\text { para inovação }\end{array}$ & 6,02 & 3 \\
\hline & & $\begin{array}{c}\text { Métricas e avaliação } \\
\text { de desempenho }\end{array}$ & 5,20 & 3 \\
\hline
\end{tabular}

PDP, percebe-se uma variação entre elas. As áreas de gestão Estratégica e de Suporte apresentaram grau 3 de maturidade, mas a área Tática-Operacional apresentou grau 2, valor que determinou a classificação do grau de desenvolvimento global da empresa (isto é, o grau de maturidade estabelecido para a gestão do PDP corresponde ao limite inferior dos graus aferidos para as áreas de gestão). A matriz $\mathrm{M}$ evidencia que as áreas do conhecimento relacionadas à área de gestão Estratégicase mostram homogeneamente evoluídas na empresa (Tabela 3) e que somente uma área do conhecimento da área Tática-Operacional se apresentou em grau inferior às demais. Os índices de desenvolvimento das áreas do conhecimento apresentaram amplitude de 2,32 pontos, considerada elevada.

A Estratégia da corporação apresentou $I D$ elevado $(6,44)$, pois a empresa declara as estratégias corporativas e a alta administração está presente no cotidiano do DP, o que facilita a disseminação das informações estratégicas pela organização. Isso traz reflexos sobre o indicador seguinte, Estratégia do projeto/produto, que também apresentou $I D$ elevado $(6,16)$. Por mais que os subprocessos envolvidos nessas áreas não sejam formalizados, a proximidade com a alta administração da empresa faz com que os problemas existentes sejam minimizados, justificando o alto desenvolvimento da área. A Empresa D não utiliza um processo de gestão de portfolio formalizado. No entanto, a Gestão do portfolio apresentou $I D$ de 6,73 , pois a maior parte dos projetos apresenta-se alinhada com a estratégia e a capacidade da empresa. Pesquisa de mercado e consumidor apresentou $I D$ elevado 
$(6,27)$ pois, embora a empresa não realize pesquisa de mercado durante a consecução dos projetos, existe uma preocupação com o comportamento dos concorrentes e com o envolvimento dos clientes na definição dos projetos a serem desenvolvidos (projetos sob demanda dos clientes), no teste do conceito e na aprovação dos protótipos.

A área de gestão Tática-Operacional, Processo sistematizado apresentou $I D$ de 5,87. A empresa implantou recentemente um método de gestão de projetos; apesar deste estar sendo aplicado em projetos mais recentes, as pessoas envolvidas encontram dificuldades em utilizá-lo plenamente. Embora o método determine os documentos a serem gerados em cada fase, os colaboradores apresentam certa resistência a adotá-los. Desta maneira, Portais de aprovação apresentou o menor ID dentre todas as áreas analisadas $(4,41)$. A empresa utiliza pontos de controle para aprovar e avaliar os projetos. Um comitê de produto se reúne para aprovar a alocação de recursos e discutir prioridades, mas não há preocupação com o registro das decisões e das lições aprendidas no projeto. A empresa não analisa o desempenho do projeto sistematicamente, o que geralmente é feito no final do desenvolvimento. Além disso, na avaliação do projeto em desenvolvimento, nota-se pouca utilização de métricas financeiras, de qualidade e de tempo.

A área Suporte, Pessoas apresentou $I D$ de 5,12. A Empresa D utiliza equipes de desenvolvimento com a identificação dos responsáveis pelo projeto. Os administradores da empresa têm certa dificuldade em gerenciar essas equipes que contam com a participação da alta administração e de diversos outros setores, no entanto, em particular nas fases de planejamento do projeto, o setor de produção não apresenta envolvimento. Organização e estruturação para $o P D P$ apresentou $I D$ de 5,37. A comunicação horizontal é realizada de maneira informal pela intranet da empresa. A mesma utiliza reuniões para discutir prioridades nos projetos e alocação de recursos, mas essa não é uma prática sistematizada, sendo direcionada à solução de problemas eventuais. Cultura e clima para a inovação apresentou $I D$ de 6,02; a empresa preocupa-se com o desenvolvimento de seu pessoal e mantem um ambiente aberto a novidades, embora não utilize prêmios para estimular a inovação. Por fim, Métricas e avaliação de desempenho apresentaram $I D$ de 5,20. De fato, a empresa não utiliza um sistema formal de avaliação e acompanhamento dos projetos e não utiliza métricas para acompanhar o andamento do desenvolvimento. A monitoração é realizada nos portais pelo comitê, mas não se trata de um subprocesso sistematizado.

\subsection{Fase 3: Consolidação de um conjunto de oportunidades de melhoria}

A aplicação da matriz $\mathrm{M}$ auxiliou na avaliação do desenvolvimento de cada área da GPDP em função da ocorrência dos problemas típicos de PDP e permitiu mensurar a maturidade da empresa em questão. As áreas críticas descritas no item anterior são as que apresentam maior relacionamento com os problemas de ocorrência mais frequente. Para reconhecer essas áreas, realizou-se uma análise em gráfico BoxPlot (Tabela 4) dos valores de $I D$ obtidos na matriz M (Figura 2).

Analisando a Figura 2, constata-se que a mediana dos $I D s$ é 5,94 pontos. Considerando-se exclusivamente essa estatística, a empresa deveria

Tabela 4. Valores de $I D$.

\begin{tabular}{cc}
\hline Item & ID \\
\hline Estratégia da corporação & 6,44 \\
Estratégia do projeto/produto & 6,16 \\
Gestão de portfólio & 6,73 \\
Pesquisa de mercado e consumidor & 6,27 \\
Processo sistematizado & 5,87 \\
Portais de aprovação & 4,41 \\
Pessoas & 5,12 \\
Organização e estruturação para o PDP & 5,37 \\
Cultura e clima para a inovação & 6,02 \\
Métricas e avaliação de desempenho & 5,2 \\
ID max & 6,73 \\
ID mim & 4,41 \\
10 quartil $^{\circ}$ Mediana & 5,24 \\
3 $^{\circ}$ quartil & 5,94 \\
Limite inferior & 6,24 \\
Limite superior & 3,75 \\
Teste comportamento ID mim & 7,74 \\
Teste comportamento ID max & 4,41 \\
Média & 6,73 \\
\hline
\end{tabular}

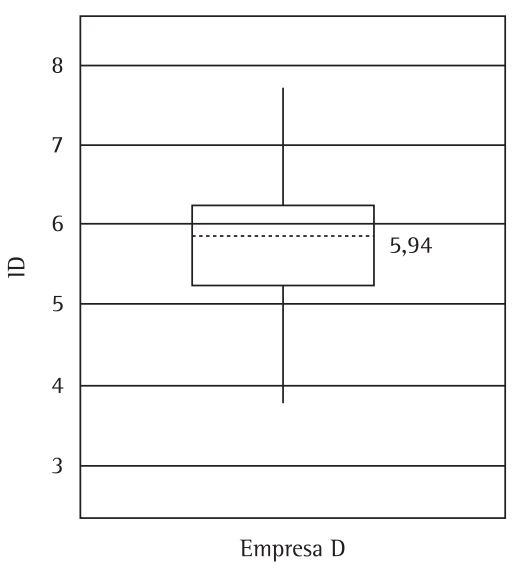

Figura 2. BoxPlot dos IDs. 
ser classificada no grau de maturidade 3; porém, a variação dos IDsse mostrou acentuada (2,32 pontos) e uma área apresentou $I D$ mais baixo (Portais de aprovação, $I D 4,41)$, o que determinou a classificação de maturidade da empresa. No BoxPlot também é possível perceber uma leve assimetria positiva na distribuição dos $I D s$, com valores elevados de $I D$ mais próximos entre si e ausência de valores distantes do conjunto. As áreas Portais de aprovação, Pessoas e Métricas e avaliação de desempenho são críticas na GPDP, dado seus valores de $I D$. Essa indicação é coerente com o estado atual da gestão da empresa, pois os portais são constantemente negligenciados e não há preocupação com o registro das decisões. A empresa preocupa-se com o desenvolvimento dos envolvidos, mas não gerencia o trabalho desenvolvido e o controle não é sistematizado. Além disso, as métricas não são utilizadas mais intensamente para avaliar o desempenho dos projetos em desenvolvimento.

\subsection{Fase 4: Determinação do peso dos critérios e atributos de priorização das oportunidades de melhoria}

Após a apresentação das alternativas de melhoria, a equipe foi solicitada a buscar um consenso sobre a importância dos atributos, formando o perfil de decisão. 0 Quadro 11 apresenta a estrutura de suporte à decisão utilizada e os resultados obtidos.

\subsection{Fase 5: Priorização das oportunidades de melhoria}

Determinado o perfil de decisão para a priorização das alternativas de melhoria, os componentes da equipe foram solicitados a analisar as alternativas de melhoria nas áreas críticas Portais de aprovação,

Quadro 11. Peso atribuído aos critérios de priorização.

\begin{tabular}{|c|c|c|c|c|}
\hline \multicolumn{5}{|c|}{ Perfil de descisão para priorização dos projetos de melhoria } \\
\hline Objetivo & Critérios & Atributos & Peso & $p a_{n}(\%)$ \\
\hline \multirow{8}{*}{$\begin{array}{c}\text { Priorizar } \\
\text { sugestões } \\
\text { de } \\
\text { melhoria }\end{array}$} & \multirow{3}{*}{$\begin{array}{l}\text { Importância } \\
\text { da } \\
\text { alternativa } \\
\text { de melhoria }\end{array}$} & $\begin{array}{l}\text { Realização das metas } \\
\text { estratégicas }\end{array}$ & 70 & 28 \\
\hline & & $\begin{array}{l}\text { Eliminação dos pontos } \\
\text { fracos de PDP }\end{array}$ & 100 & 40 \\
\hline & & $\begin{array}{c}\text { Impacto na estrutura } \\
\text { organizacional }\end{array}$ & 80 & 32 \\
\hline & \multicolumn{2}{|c|}{ Importância do primeiro critério } & 250 & 61 \\
\hline & \multirow{3}{*}{$\begin{array}{l}\text { Esforço da } \\
\text { alternativa } \\
\text { de melhoria }\end{array}$} & Risco técnico & 30 & 19 \\
\hline & & $\begin{array}{l}\text { Necessidade de RH } \\
\text { qualificado }\end{array}$ & 100 & 63 \\
\hline & & $\begin{array}{l}\text { Necessidade de } \\
\text { investimento }\end{array}$ & 30 & 19 \\
\hline & \multicolumn{2}{|c|}{ Importância do segundo critério } & 160 & 39 \\
\hline
\end{tabular}

Métricas e avaliação de desempenho e Pessoas na matriz P. As áreas foram abordadas por ordem de criticidade e todas as práticas foram exploradas. 0 resultado dessa etapa esta apresentado na Tabela 5.

\subsection{Fase 6: Ranqueamento e definição do portfólio de oportunidades de melhoria}

A matriz P (Tabela 5) favorece a organização das alternativas em categorias, o que dificulta a visualização dos resultados finais. 0 histograma na Figura 3 organiza as alternativas em ordem decrescente de valor de $P T_{i}$, permitindo uma análise imediata das alternativas de melhoria.

A Empresa D selecionou as dez primeiras oportunidades para compor um portfolio de oportunidades de melhoria. Analisando o ponto de corte adotado pela Empresa D, constata-se que a área Portais de aprovação teve quatro oportunidades listadas no portfolio de melhorias, sendo duas relacionadas às fases iniciais do desenvolvimento e duas relacionadas à execução dos gates técnicos e gerenciais. A área Pessoas teve quatro indicações, duas delas relacionadas ao gerenciamento de recursos humanos e duas relacionadas com o comprometimento dos recursos. A área Métricas e avaliação de desempenho teve duas alternativas elencadas no portfolio, uma oportunidade relacionada com a formalização de um sistema de avaliação de desempenho e outra com a avaliação e o acompanhamento dos projetos e produtos.

\subsection{Avaliação do método de análise de maturidade e priorização de melhorias}

Um questionário qualitativo aberto foi aplicado ao grupo envolvido na análise de maturidade com o objetivo de captar percepções e sugestões relacionadas à aplicabilidade do método. Essa estratégia de avaliação foi escolhida em função do reduzido número de pessoas que participaram da aplicação do método. 0 grupo foi solicitado a opinar sobre três tópicos: complexidade de aplicação, grau de detalhamento e amplitude do método.

Em relação à complexidade, a equipe afirmou que o método é de aplicação simples. Não foram apontadas dificuldades na utilização dos três instrumentos deste método: (i) questionário de problemas típicos para avaliar a sofisticação das áreas da GPDP (resultado da primeira macroetapa), (ii) preenchimento das matrizes MAUT e (iii) preenchimento da matriz $\mathrm{P}$ para determinar um ordenamento prioritário das oportunidades de melhoria (resultado da segunda macroetapa). 
Tabela 5. Matriz de priorização das oportunidades de melhoria.

\begin{tabular}{|c|c|c|c|c|c|c|c|c|}
\hline \multicolumn{9}{|c|}{ Matriz de Priorização } \\
\hline Critérios & & $\begin{array}{l}\text { ortância } \\
\text { reendim }\end{array}$ & & & $\begin{array}{ll}\text { sforço c } \\
\text { reendim }\end{array}$ & & \multirow{3}{*}{ 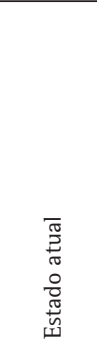 } & \multirow{3}{*}{ 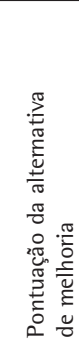 } \\
\hline \multirow[t]{2}{*}{ Atributos } & 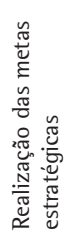 & 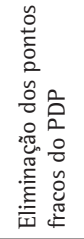 & 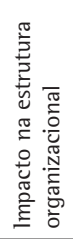 & 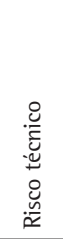 & 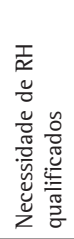 & 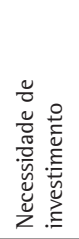 & & \\
\hline & $28 \%$ & $40 \%$ & $32 \%$ & $19 \%$ & $63 \%$ & $19 \%$ & & \\
\hline \multicolumn{9}{|l|}{ Portais de aprovação } \\
\hline \multicolumn{9}{|l|}{ Realizar gates de aprovação } \\
\hline Realizar gates gerenciais & 3 & 9 & 3 & 0 & 9 & 0 & 2526,5 & 27855 \\
\hline Realizar gates técnicos & 3 & 9 & 9 & 0 & 3 & 0 & 2478,1 & 22786 \\
\hline \multicolumn{9}{|l|}{ Documentar as fases do DP } \\
\hline Documentar o planejamento estratégico do produto & 9 & 9 & 3 & 1 & 0 & 0 & 2207,6 & 16044 \\
\hline Documentar o planejamento do projeto & 9 & 9 & 9 & 3 & 9 & 0 & 2434,3 & 36970 \\
\hline Documentar o projeto informacional & 9 & 9 & 9 & 3 & 9 & 0 & 1829,6 & 27788 \\
\hline Documentar o projeto conceitual & 3 & 3 & 3 & 1 & 3 & 0 & 1634,5 & 8275 \\
\hline Documentar o projeto detalhado & 9 & 9 & 9 & 9 & 9 & 0 & 1391,3 & 22695 \\
\hline Documentar a preparação para a produção & 9 & 9 & 1 & 3 & 3 & 0 & 1023,7 & 9087 \\
\hline Documentar o lançamento do produto & 9 & 3 & 9 & 0 & 9 & 9 & 935,1 & 13009 \\
\hline Documentar o acompanhamento do produto & 9 & 9 & 3 & 0 & 1 & 3 & 1342,4 & 11098 \\
\hline Documentar a descontinuação do produto & 3 & 3 & 1 & 0 & 0 & 0 & 729,4 & 1721 \\
\hline \multicolumn{9}{|l|}{ Pessoas } \\
\hline \multicolumn{9}{|l|}{ Gerenciamento dos recursos humanos } \\
\hline Planejar recursos humanos & 9 & 9 & 9 & 3 & 9 & 1 & 1345,6 & 20689 \\
\hline Desenvolver recursos humanos & 9 & 9 & 9 & 9 & 9 & 9 & 2303,1 & 41456 \\
\hline Gerenciar equipe de projeto & 9 & 9 & 9 & 3 & 9 & 9 & 2213,6 & 37354 \\
\hline \multicolumn{9}{|l|}{ Determinar formalmente a participação no DP } \\
\hline Determinar formalmente os personagens do processo & 9 & 9 & 9 & 1 & 3 & 0 & 1259,5 & 13933 \\
\hline \multicolumn{9}{|l|}{ Empenhar recursos humanos } \\
\hline Empenhar recursos para projeto de DP & 9 & 3 & 9 & 1 & 3 & 9 & 1222,4 & 12652 \\
\hline Comprometer os principais personagens com o DP & 9 & 3 & 3 & 0 & 9 & 9 & 2187,1 & 26229 \\
\hline Comprometer equipe multifuncional & 9 & 9 & 9 & 3 & 9 & 3 & 1864,9 & 29373 \\
\hline \multicolumn{9}{|l|}{ Métricas e avaliação de desempenho } \\
\hline \multicolumn{9}{|l|}{ Formalizar um sistema de avaliação de desempenho } \\
\hline Utilizar um sistema formal de avaliação de desempenho & 9 & 9 & 3 & 9 & 9 & 3 & 2696,2 & 40322 \\
\hline $\begin{array}{l}\text { Utilizar métricas claras e objetivas para avaliar projeto e } \\
\text { produto }\end{array}$ & 3 & 3 & 9 & 9 & 1 & 1 & 2208,4 & 16386 \\
\hline \multicolumn{9}{|l|}{ Avaliar/acompanhar o desempenho do projeto/produto } \\
\hline Avaliar/acompanhar o desempenho do projeto & 9 & 9 & 9 & 3 & 3 & 0 & 2478,7 & 28350 \\
\hline Avaliar/acompanhar o desempenho do produto & 3 & 3 & 1 & 1 & 1 & 1 & 2326,7 & 7818 \\
\hline
\end{tabular}

Em relação ao grau de detalhamento, o grupo afirmou que os IDs permitiram uma análise detalhada das áreas de gestão e do conhecimento da GPDP, identificando as áreas críticas. A equipe afirmou, ainda, que algumas práticas já haviam sido percebidas como oportunidades de melhoria para a GPDP; os IDs forneceram uma evidência quantitativa nesse sentido, permitindo distinguir a criticidade entre melhores práticas para a empresa.

Em relação à amplitude do método, as pessoas envolvidas afirmaram que a Referência de Melhores Práticas presente na estrutura da matriz M garantiu a abrangência de análise da GPDP. Os participantes destacaram que ao discutir a frequência da ocorrência de problemas típicos, outras práticas vieram à tona, expondo diferentes aspectos da gestão a serem potencialmente melhorados. Além disso, as observações qualitativas geradas durante a aplicação do questionário fechado (Quadro 10) facilitaram a interpretação dos resultados dos índices calculados, demonstrando que a análise qualitativa deve ser conduzida paralelamente à análise de maturidade quantitativa proporcionada pelo método aqui proposto. 


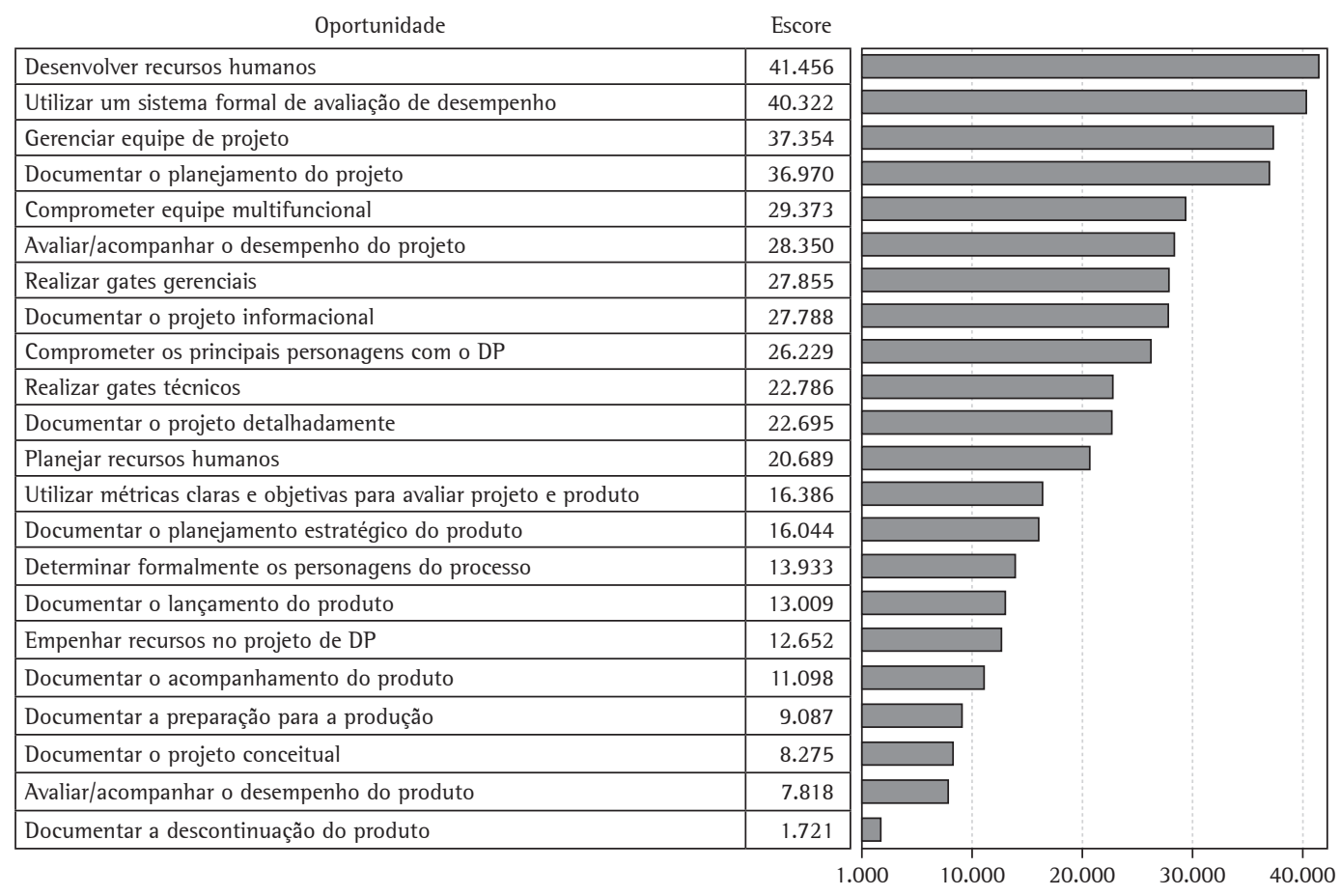

Figura 3. Ranqueamento das oportunidades de melhoria.

\section{Conclusões}

Neste artigo apresentou-se um método de análise de maturidade e priorização de melhorias. Tal método visa auxiliar gestores do PDP a identificar as oportunidades de melhoria e ordená-las conforme as prioridades da empresa. Para atender esses objetivos, o método foi organizado em duas macroetapas, subdivididas em seis fases. Na primeira macroetapa realiza-se a coleta de dados e análise da maturidade da GPDP da empresa. A segunda macroetapa orienta-se à geração de um portfolio de oportunidades de melhorias.

0 método proposto apresenta pelo menos duas contribuições relevantes para a área de análise de maturidade do PDP. Primeiro, avaliação da maturidade é realizada através da identificação da ocorrência de problemas no PDP da empresa e da determinação de sua intensidade, utilizando um instrumento organizado e abrangente de coleta de dados. Para os gestores é relativamente fácil abordar os problemas existentes em seus processos. Segundo, pelo método obtem-se, na realização de suas etapas, resultados de uma extensa análise de relacionamentos entre problemas de PDP e práticas melhores, destinadas a abrandá-los ou mesmo eliminá-los. A análise, desenvolvida por um grupo qualificado de especialistas, é utilizada na determinação do grau de maturidade e pode ser usada na análise de empresas dos mais diversos segmentos.
A proposição de um método de fácil utilização, que permite a avaliação de maturidade em função da ocorrência de problemas solucionáveis pelas melhores práticas e prioriza as oportunidades de melhoria surgiu da constatação da existência de uma lacuna nos modelos de maturidade disponíveis na literatura no que diz respeito à tomada de decisão posterior à análise de maturidade. 0 método propõe-se a simplificar as condições de coleta de dados para análise e contribuir para a tomada de decisões. Assim as ações de melhoria poderão ser sustentáveis e os recursos, utilizados racionalmente, ou seja, aplicados nas práticas que são efetivamente essenciais para a gestão da empresa.

Uma aplicação real ilustra asetapasmetodológicas propostas. 0 estudo de caso reportado foi realizado em uma empresa desenvolvedora de software. Os resultados obtidos atestam a capacidade analítica do método proposto.

Três desdobramentos futuros da presente pesquisa são visualizáveis a partir da análise detalhada do método proposto. 0 primeiro, no sentido de aproximar o método proposto das abordagens de intervenção para a melhoria do PDP (e.g. os trabalhos de CAFFYN, 1998; RENTES, 2000; GUSBERTI, 2006), pois esses trabalhos enfocam todas as etapas do ciclo de melhoria. A contribuição do presente método seria em relação às fases de diagnóstico e proposição de melhorias 
das abordagens desses autores. 0 segundo desdobramento seria inserir ferramentas aplicáveis a cada uma das 95 MPs presentes nesta proposta, criando um repositório de métodos e ferramentas utilizáveis na gestão do PDP, o que facilitaria o planejamento das melhorias a serem realizadas. Como terceiro desdobramento, indica-se a criação de descrições textuais para os cinco graus de maturidade do modelo proposto, semelhantes às existentes nos modelos de capacidade e nas grades de maturidade.

\section{Referências}

ADAMS-BIGELOW, M. First results From the 2003 Comparative Performance Assessment Study, 2005. In: KAHN, B. K. The PDMA Hand Book of New Product Development. 2 ed. New Jersey: John Wiley and Sons, 2005.

AGOSTINETTO, J. S.; AMARAL, D. C. Diagnóstico das atividades de melhoria contínua no processo de desenvolvimento de produtos. In: CONGRESSO BRASILEIRO DE GESTÃO DE DESENVOLVIMENTO DE PRODUTO - CBGDP, 5., 2005, Curitiba. Anais...

AMARAL, D. C.; ROZENFELD, H. Integrating new product development process references with maturity and changes management. In: INTERNATIONALCONFERENCE ON ENGINEERING DESIGN - ICED, 7., 2007, Paris-FR. Anais...

BARCZAK, G.; KAHN, K.; MOSS, R. An Exploratory Investigation of NPD Practices in Non-profit Organization. The Journal of Product Innovation and Management, v. 23, p. 512-527, 2006.

BAXTER, M. Projeto de produto: um guia prático para o design de novos produtos. 2 ed. São Paulo: Edgard Blücher Ltda, 1998.

CAFFYN, S. J. The scope for the application of continuous improvement to the process to the new product development. 1998. Tese (Doutorado) - University of Bringhton, UK.

CERVO, A. L.; BERVIAN, P. A. Metodologia científica. 4 ed. São Paulo: Makron Books, 1996.

COOPER, R. G.; KLEINSCHMIDT, E. J. An investigating into a New Product Process: Steps, Deficiencies and Impact. The Journal of Product Innovation and Management, v. 3, p. 71-85, 1986.

COOPER, R. G.; EDGETT, S. J.; KLEINSCHMIDT, E. J. Benchmarking best NPD practices 1. Research - Technology Management, v. 47, n. 1, p. 31-43, 2004 a.

COOPER, R. G.; EDGETT, S. J.; KLEINSCHMIDT, E. J. Benchmarking best NPD practices 11. Research - Technology Management, v. 47, n. 3, p. 50-59, 2004 b.

COOPER, R. G.; EDGETT, S. J.; KLEINSCHMIDT, E. J. Benchmarking best NPD practices III. Research - Technology Management, v. 47, n. 6, p. 43-55, 2004 c.

CAPABILITY MATURITY MODEL INTEGRATION - CMMI. Version 1.1. Pittsburgh: Carnegie Mellon Institute, mar. 2002. Disponível em:<http://www.sei.cmu.edu/ reports/02tr029.pdf>. Acesso em: 15 set. 2009.

CROSBY, B. P. Qualidade é investimento: a arte de garantir a qualidade. Rio de Janeiro: José Olympo, 1984.
DOOLEY, K.; SUBRA, A.; ANDERSON, J. Maturity and its impact on the new product development project performance. Research in Engineering Design, v. 13, p. 23-29, 2001.

ECHEVESTE, M. E. S. Uma abordagem apara e estruturação e controle do processo de desenvolvimento de produtos. 2003. Tese (Doutorado) - PPGEP/UFRGS, Porto Alegre.

FRASER, P.; MOULTRIE, J.; GREGORY, M. The use of maturity models / grids as a tool in assessing product development capability. IEEE Institute of Electrical and Electronics Engineers, 2002. Disponível em: http://ieeexplore.ieee. org/stamp/stamp.jsp?tp=\&arnumber=1038431\&isnumb er=22257. Acesso em: 15 set. 2009.

GONÇALVES, J. E. L. Processos: que processos? Revista de Administração de Empresas, v. 40, n. 4, p. 8-19, 2000.

GRIFFIN, A. PDMA Research on the New Product Development Practices: Update Trends and Benchmarking Best Practices. The Journal of Product Innovation and Management, v. 14, p. 429-458, 1997.

GUSBERTI, T. D. H. Modelo de intervenção para o processo de desenvolvimento de produto farmacêutico para pequenas e médias empresas. 2006. Dissertação (Mestrado) PPGEP, UFRGS, Porto Alegre.

JUCÁ Jr., A. S.; AMARAL, D. C. Estudos de caso de maturidade em gestão de projetos em empresas de base tecnológica. In: ENCONTRO NACIONAL DE ENGENHARIA DE PRODUÇÃO, 25., 2005. Anais... Porto Alegre - RS: ABEPRO, 2005.

KAHN, K. An Exploratory Investigation of New Product Development Forecasting Practices. The Journal of Product Innovation and Management, v. 19, p. 133-143, 2001.

KAHN, K.; BARZACK, G.; MOSS, R. Establishing a NPD Best practice Framework. The Journal of Product Innovation and Management, v. 23, p. 106-116, 2006.

MIN, H. International Supplier Selection: a Multiattribute Utility Approach. International Journal of Product Development and Logistic Management, v. 24, n. 5, p. 24-33, 1994.

MITCHELL, M. L.; JOLLEY, J. M. Research design explained. 5 ed. Toronto: Wadsworth Publishing, 2003.

MOULTRIE, J.; CLARCKSON, P. J.; PROBERT, D. A Tool to Evaluate Design Performance in SMEs. International Journal of Productivity and Performance Management, v. 55, n. 3/4, p. 184-216, 2006.

MUNDIM, A. P. F. et al. Aplicando o cenário de desenvolvimento de produtos em um caso prático de capacitação Profissional. Gestão \& Produção, v. 9, n. 1, p. 1-16, 2002.

NILSSON-WITELL, L.; ANTONI, M.; DAHLGAARD, J. J. Continuous improvement in product development. International Journal of Quality \& Reliability Management, v. 22, n. 8, p. 753-768, 2005.

OAKLEY, P. Hight-Tech NPD Success through Fasters Overseas Launch. Journal of Product \& Brand Management, v. 6, n. 4, p. 260-274, 1997.

PAGE, A. Assessing New Product Development Practices and Performance: Establishing Crucial Norms. The Journal of Product Innovation and Management, v. 10, p. 273-290, 1993.

PAHL, G. et al. Projeto na engenharia: fundamentos do desenvolvimento de produtos, métodos e aplicações. São Paulo: Editora Edgar Blücher Ltda. 1 ed., 2005. 
PAULA, 1. C.; RIBEIRO, J. L. D. A Proposal of a Reference Model for the Pharmaceutical PDP Management. Brazilian Journal of Operations \& Production Management, v. 4, n. 2, p. 5-32, 2007.

PDMABoK. The Body of Knowledge of PDMA, 2003. Disponivel em: <http://www.pdmabok.org/.> Acesso em: 11 abr. 2007.

PROJECT MANAGEMENT INSTITUTE - PMI. A guide to the project management body of knowledge. PMBoK. 3 ed. [S.I.]: [s.n.], 2004.

PATTERSON, M. L.; FENOGLIO, J. A. Leading Product Innovation. Accelerating Growht in the Product Based Business. New York: John Wiley \& Sons Inc., 1999.

ROMANO, L. N. Modelo de referência para o processo de desenvolvimento de máquinas agrícolas. 2003. Tese(Doutorado) - PPGEM, UFSC, Florianópolis.

ROZENFELD, H.; SCALICE, R.; AMARAL, D. C. Proposta de um modelo de maturidade para o processo de desenvolvimento de produtos. In: CONGRESSO BRASILEIRO DE GESTÃO DE DESENVOLVIMENTO DE PRODUTO - CBGDP, 5., 2005, Curitiba. Anais...

ROZENFELD, H. et al. Gestão de desenvolvimento de produtos: Uma referencia para a melhoria do processo. São Paulo: Editora Saraiva, 2006.
SALVIANO, C. F. Uma proposta orientada a perfis de capacidade de processo para evolução de melhoria de processo de software. 2006. Tese (Doutorado) - FEEC, UNICAMP, Campinas.

THEVENOT, H. J. et al. A Multiattribute Utility Theory: Based Approach to Product line Consolidation and Selection. In: INTERNATIONAL DESIGN ENGINEERING AND TECHNICAL CONFERENCE \& COMPUTER AND INFORMATION ENGINEERING CONFERENCE, Sep 10-13, 2006, Philadelphia, Pennsylvania, USA.

YIN, R. K. Case Study Research: Design and Methods. 3 ed. California: Sage Publications, 2002.

\section{Agradecimentos}

Os autores agradecem as sugestões de melhoria no artigo feitas pelos revisores. A pesquisa do Prof. Flávio Fogliatto é financiada pelo $\mathrm{CNPq}$ (Processos PQ 301380/2008-2 e Universal 473846/2007-1) e pela CAPES (Processo PE 1378/2008). A pesquisa da Prof. Istefani de Paula é financiada pelo CNPq (Processo 570628/2008-3 MCT/CNPq 06/2008).

\title{
A method for maturity measurement and ranking of improvement projects in Product Development Management
}

\begin{abstract}
The Product Development Process (PDP) has increasing influence on companies' strategic results. Eliciting improvement opportunities in PDP is a non-trivial task, and has motivated researchers to propose approaches to rationalize the effort of sophisticating PDP Management (PDPM). This paper presents a method to measure the maturity of the PDPM and to prioritize improvement projects in that area. The maturity measurement is performed by quantifying relationships between the PDPM's knowledge areas and typical problems present in PDP. To rank improvement opportunities, critical knowledge areas are deployed into Best Practices, to which improvement opportunities are related and prioritized using a Multi-attribute Utility method. The proposed method is illustrated in a case study centered on a software development industry.
\end{abstract}

Keywords

PDP management. PDP improvement. Maturity models. 
Apêndice 1. Questionário de problemas típicos contendo a frequência da ocorrência dos problemas da Empresa D.

\begin{tabular}{|c|c|c|}
\hline \multicolumn{2}{|r|}{ Empresa D } & \multirow{2}{*}{$\begin{array}{c}\text { Frequência } \\
\text { de } \\
\text { ocorrência }\end{array}$} \\
\hline \multicolumn{2}{|r|}{ Problemas típicos de PDP } & \\
\hline $\mathrm{P} 1$ & Falta de definições estratégicas no início do processo de desenvolvimento de produto (PDP) & 4 \\
\hline $\mathrm{P} 2$ & Falta de foco no negócio & 3 \\
\hline P3 & $\begin{array}{l}\text { Não há envolvimento e comprometimento da alta administração e dos investidores na fase de planejamento tornando as } \\
\text { decisões tardias }\end{array}$ & 1 \\
\hline P4 & Desconhecimento das estratégias da empresa por parte da equipe de desenvolvimento & 8 \\
\hline P5 & Falta a percepção de que o PDP é um processo de negócio & 4 \\
\hline P6 & 0 produto do concorrente é lançado primeiro & 1 \\
\hline P7 & 0 período para retorno do investimento é grande & 5 \\
\hline P8 & Falta de cumprimento dos prazos nas etapas do projeto (eficiência), tornando o tempo de desenvolvimento elevado & 9 \\
\hline P9 & 0s projetos não são viáveis economicamente & 1 \\
\hline $\mathrm{P} 10$ & $\begin{array}{l}\text { Falta de uma metodologia formal de desenvolvimento de produtos (sequência lógica de etapas e de atividades } \\
\text { documentadas e divulgada entre todos os membros da empresa) }\end{array}$ & 6 \\
\hline $\mathrm{P} 11$ & Falta de planejamento estratégico do produto & 3 \\
\hline P12 & $\begin{array}{l}\text { Falta de uma política definida de pesquisa de mercado pró-ativa que oriente as fases iniciais do PDP (verificação de } \\
\text { tendências de mercado) }\end{array}$ & 8 \\
\hline P13 & Não há preocupação sistemática em estabelecer contato com os clientes & 4 \\
\hline P14 & 0 projeto não atende as necessidades dos clientes & 4 \\
\hline P15 & Os produtos são ultrapassados (tecnologia e qualidade) & 1 \\
\hline P16 & 0 produto não é competitivo (preço, custo e qualidade) & 1 \\
\hline P17 & Falta orientação para o mercado nas fases iniciais do PDP (sem identificação das tendências de mercado) & 2 \\
\hline P18 & $\begin{array}{l}\text { Falta divulgação de informações sobre os produtos (em desenvolvimento e em comercialização) entre os colaboradores } \\
\text { da empresa }\end{array}$ & 9 \\
\hline P19 & Falta uma matriz de responsabilidades que distribua as tarefas e as responsabilidades dos envolvidos no PDP & 9 \\
\hline P20 & $\begin{array}{l}\text { Há excesso de níveis hierárquicos nos setores funcionais, burocratizando a tomada de decisão e restringindo a } \\
\text { comunicação vertical entre os diferentes níveis da estrutura do PDP }\end{array}$ & 2 \\
\hline P21 & 0 projeto é incompatível com a capacidade de produção & 7 \\
\hline P22 & Existe um excesso de centralização do trabalho de desenvolvimento em algum setor ou área & 7 \\
\hline P23 & Faltam definição e detalhamento (uma formalização mínima) das atividades em cada fase do pré-desenvolvimento & 5 \\
\hline P24 & Falta um gerenciamento que avalie o impacto das alterações de mudança de escopo do projeto (tempo, custo e qualidade) & 4 \\
\hline P25 & 0 processo depende essencialmente da capacidade pessoal e da memória dos envolvidos & 4 \\
\hline P26 & 0 processo de pré-desenvolvimento não se inicia pelo setor mais adequado & 1 \\
\hline P27 & Não há definição clara das diretrizes estratégicas e prioridades do projeto & 5 \\
\hline P28 & $\begin{array}{l}\text { Falta uma sistemática formal para o armazenamento do conhecimento gerado nas fases (registro das decisões tomadas e } \\
\text { das lições aprendidas) }\end{array}$ & 7 \\
\hline P29 & Falta um método consistente e sistemático para orientar a tomada de decisões acarretando atrasos no projeto & 6 \\
\hline P30 & A aprovação de capital para investimentos não é realizada no tempo requerido & 2 \\
\hline P31 & Falta de autonomia por parte da equipe (consequência da cultura da organização) & 4 \\
\hline P32 & Há desmotivação nos trabalhos em equipe & 1 \\
\hline P33 & Falta de preparo do coordenador do projeto e dos envolvidos no PDP para executar suas funções (gerando improvisação) & 9 \\
\hline P34 & A fluxo de informações entre marketing e engenharia não é sistemático e organizado & 1 \\
\hline P35 & $\begin{array}{l}\text { Não há estrutura formalizada de permuta, controle e armazenamento de conhecimento inter e intraprojeto que dê } \\
\text { suporte à utilização de experiências de projetos anteriores }\end{array}$ & 8 \\
\hline P36 & Falta de gerenciamento das equipes entre funções e intrafuncional & 3 \\
\hline P37 & A busca de informação não é suficiente & 8 \\
\hline P38 & $\begin{array}{l}\text { Há atrasos ou inadequada circulação de informação durante a execução do projeto (os colaboradores trabalham com } \\
\text { informaçoses desatualizadas) }\end{array}$ & 5 \\
\hline P39 & Falta integração no sistema de informação (não atende as necessidades do projeto) & 9 \\
\hline P40 & Falta análise de desempenho no cumprimento das etapas e nos resultados finais & 9 \\
\hline P41 & 0 trabalho em equipe não é eficaz & 6 \\
\hline P42 & Perda de tempo devido a falta de sincronização no fluxo de trabalho & 9 \\
\hline P43 & Pouca utilização de ferramentas aplicadas ao DP & 6 \\
\hline P44 & Falta de conhecimento de ferramentas aplicadas ao desenvolvimento das atividades do PDP & 3 \\
\hline P45 & Falta de equipamentos adequados (os computadores utilizados precisam ser atualizados em termos de hardware e software) & 1 \\
\hline P46 & Não há acompanhamento sistemático do desempenho dos produtos (em relação ao mercado e à concorrência) & 3 \\
\hline P47 & Controle baseado exclusivo no cronograma & 9 \\
\hline P48 & Falta um procedimento sistemático para avaliação das falhas e soluções adotadas nos produtos & 9 \\
\hline P49 & Falta de rigor na busca (individual ou em grupo) das causas das falhas que ocorrem nos produtos & 9 \\
\hline P50 & Falta sistemática para avaliar o desempenho do projeto através de métricas (somente no final do projeto) & 9 \\
\hline P51 & Falta geração de idéias suficientes & 1 \\
\hline P52 & Falta adequada seleção das melhores idéias de produto & 5 \\
\hline
\end{tabular}


Apêndice 2. Descrição textual das áreas de gestão e de conhecimento da Referência de Melhores Práticas (RMP).

\begin{tabular}{|c|l|}
\hline \multicolumn{2}{|c|}{ Descrição textual das áreas de gestão e de conhecimento da Referência de Melhores Práticas (RMP) } \\
\hline $\begin{array}{c}\text { Estratégia da } \\
\text { corporação }\end{array}$ & $\begin{array}{l}\text { Esta área do conhecimento compreende as habilidades (competências) técnicas necessárias para a empresa } \\
\text { definir os objetivos e metas estratégicas, estruturadas em observações externas e internas à empresa, para } \\
\text { orientá-la nos negócios (refletindo missão, visão e valores da corporação), planejar e organizar as ações em } \\
\text { função dos seus objetivos, comunicar para a toda a organização seus objetivos e metas e definir métricas } \\
\text { (indicadores) para mensurar a sua realização. }\end{array}$ \\
\hline $\begin{array}{c}\text { Estratégia do } \\
\text { projeto/produto }\end{array}$ & $\begin{array}{l}\text { Esta área do conhecimento compreende as habilidades (competências) técnicas necessárias para desdobrar as } \\
\text { metas da organização em objetivos estratégicos para os projetos/produtos ou as linhas de produto, levantar } \\
\text { informações externas e internas, realizar análise das competências econômicas, produtivas e organizacionais } \\
\text { para melhor detalhar as necessidades e os benefícios a serem realizados, planejar as atividades em uma } \\
\text { estrutura hierárquica, definir métricas (indicadores), avaliar e acompanhar o trabalho de desenvolvimento } \\
\text { por todo o seu ciclo de vida e nomear os principais personagens para conduzir o o projeto/produto. }\end{array}$ \\
\hline
\end{tabular}
Esta área do conhecimento compreende as habilidades (competências) técnicas necessárias para desdobrar as metas da organização em objetivos estratégicos para os projetos/produtos ou as linhas de produto, compreende habilidades para levantar informações externas e internas, realizar análise das competências Gestão de portfólio econômicas, produtivas e organizacionais para melhor detalhar as necessidades e os benefícios a serem realizados pelo projeto/produto, planejar as atividades em uma estrutura hierárquica, definir métricas (indicadores), avaliar e acompanhar o trabalho de desenvolvimento do projeto/produto por todo o seu ciclo de vida e nomear os principais personagens para conduzir o projeto.

Esta área do conhecimento compreende as habilidades (competências) técnicas necessárias para adquirir informações do mercado, de inovações tecnológicas, dos concorrentes e dos potenciais consumidores, analisar essas informações, identificar e entender as oportunidades (em função das necessidades dos

Pesquisa de mercado e consumidor

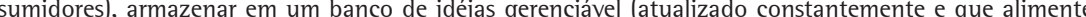
o processo de definição estratégica e de seleção e priorização de projetos), determinar o mix de variáveis do produto (relativo à qualidade, à embalagem e ao acabamento, ao preço e às políticas de distribuição), realizar testes de mercado, validar requisitos, verificar a aceitação do conceito e do produto e monitorar o desempenho dos produtos no mercado.

Esta área do conhecimento compreende as habilidades (competências) técnicas necessárias para utilizar um método padrão de gestão de projetos de desenvolvimento de produto estratificado em fases, voltado para a identificação das oportunidades com forte foco no cliente, suportar e documentar as atividades do pré-desenvolvimento, do desenvolvimento e do pós-desenvolvimento, estabelecer participação dos setores envolvidos nestas fases e gerenciar vários projetos simultaneamente, identificar/reconhecer no método de $\mathrm{DP}$ as ferramentas de auxílio ao projeto de engenharia (CAD, CAE, QFD, FMEA e outras), de gestão de projetos, de gestão da inovação, de gestão de documentos, envolver os setores funcionais na participação das atividades, formalizando as ações entre os envolvidos, e gerenciar as interfaces dos processos de negócio que contribuem para o DP.

Processo

sistematizado

Esta área do conhecimento compreende as habilidades (competências) técnicas necessárias para avaliar a execução das atividades de desenvolvimento do projeto através de gates (portais) gerenciais (para avaliar a completude e a qualidade da execução através de critérios claros e previamente definidos) e gates técnicos

Portais de aprovação (para avaliar a realização e a qualidade de execução dos requisitos técnicos do produto), realizar portais de aprovação contando com a participação de equipes multifuncionais e registro das lições aprendidas em cada ponto de decisão. Esta área do conhecimento abrange a competência de documentar as decisões tomadas na forma de documentos específicos de cada fase.

\begin{tabular}{|c|l|}
\hline Pessoas & $\begin{array}{l}\text { Esta área do conhecimento compreende as habilidades (competências) técnicas necessárias para gerenciar } \\
\text { os recursos humanos necessários para a execução do projeto (planejar, desenvolver e gerenciar a equipe de } \\
\text { projeto), comprometer formalmente os integrantes da equipe de projeto (por todo o ciclo de vida do projeto) } \\
\text { e os recursos humanos dos setores funcionais e a alta administração para compor uma equipe de projeto } \\
\text { multifuncional desde o planejamento do empreendimento até a comercialização do produto. }\end{array}$ \\
\hline $\begin{array}{c}\text { Organização } \\
\text { para o PDP }\end{array}$ & $\begin{array}{l}\text { Esta área do conhecimento compreende as habilidades (competências) técnicas necessárias para alocar/ } \\
\text { definir recursos para o pré-desenvolvimento, o desenvolvimento e pós-desenvolvimento, formalizar um } \\
\text { sistema de suporte ao desenvolvimento de produtos, facilitar a gestão da informação em um ambiente de } \\
\text { multiprojetos concomitantes, estruturar o trabalho de desenvolvimento de produtos, organizar a equipe de } \\
\text { projetos e utilizar facilitadores extra processo para agilizar as atividades de desenvolvimento. }\end{array}$ \\
\hline $\begin{array}{c}\text { Cultura e clima para } \\
\text { a inovação }\end{array}$ & $\begin{array}{l}\text { Esta área do conhecimento compreende as habilidades (competências) técnicas necessárias para } \\
\text { incentivar o trabalho de desenvolvimento de produtos com prêmios de incentivo, fortalecer o trabalho } \\
\text { de pré-desenvolvimento, encorajar a inovação, educar (treinar) e conscientizar as pessoas envolvidas no } \\
\text { processo, reconhecer a importância de cada fase do PDP, instaurar um sistema contínuo de aperfeiçoamento } \\
\text { das pessoas envolvidas, disseminando os valores e a cultura organizacional. }\end{array}$ \\
\hline $\begin{array}{c}\text { Métricas e avaliação } \\
\text { de desempenho }\end{array}$ & $\begin{array}{l}\text { Esta área do conhecimento compreende as habilidades (competências) técnicas necessárias para utilizar um } \\
\text { sistema formal de avaliação de desempenho do PDP, determinar métricas financeiras e não financeiras com } \\
\text { medidas claras e objetivas, avaliar e acompanhar o desempenho do projeto e do produto durante todo o } \\
\text { ciclo de vida de ambos. }\end{array}$ \\
\hline
\end{tabular}

